OPEN ACCESS

Edited by:

Tomonori Saito,

Oak Ridge National Laboratory (DOE),

United States

Reviewed by:

Lu Han,

Oak Ridge National Laboratory (DOE),

United States

Rose Ruther,

Solid Power, United States

${ }^{*}$ Correspondence

Daniel T. Hallinan Jr.

dhallinan@eng.famu.fsu.edu

Specialty section:

This article was submitted to

Electrochemical Energy Conversion

and Storage,

a section of the journal

Frontiers in Energy Research

Received: 04 June 2020

Accepted: 26 August 2020

Published: 24 September 2020

Citation:

Kim K, Kuhn L, Alabugin IV and

Hallinan DT (2020) Lithium Salt

Dissociation in Diblock Copolymer

Electrolyte Using Fourier Transform

Infrared Spectroscopy.

Front. Energy Res. 8:569442.

doi: 10.3389/fenrg.2020.569442

\section{Lithium Salt Dissociation in Diblock Copolymer Electrolyte Using Fourier Transform Infrared Spectroscopy}

\author{
Kyoungmin Kim ${ }^{1,2}$, Leah Kuhn ${ }^{3}$, Igor V. Alabugin ${ }^{3}$ and Daniel T. Hallinan Jr. ${ }^{1,2 *}$ \\ ${ }^{1}$ Department of Chemical and Biomedical Engineering, Florida A\&M University-Florida State University College of Engineering, \\ Tallahassee, FL, United States, ${ }^{2}$ Aero-Propulsion, Mechatronics and Energy Center, Florida State University, Tallahassee, FL, \\ United States, ${ }^{3}$ Department of Chemistry and Biochemistry, Florida State University, Tallahassee, FL, United States
}

Polymer electrolytes are important materials in the manufacture of all-solid-state batteries due to their ionic conductivity, achieved by doping the polymer with salt, and mechanical strength, achieved by use of a block copolymer with a rigid block. High salt concentration is advantageous to achieve high ionic conductivity, but it makes estimation of battery performance difficult due to the breakdown of dilute-solution theory, which assumes complete ion dissociation. Therefore, practical battery design would benefit from an empirical understanding of the relationship between ion dissociation and salt concentration in block copolymer electrolyte. In this study, the dissociation of lithium bis(trifluoromethanesulfonyl)imide (LiTFSI) in polystyrene (PS) poly(ethylene oxide) (PEO) diblock copolymer electrolyte was investigated using Fourier transform infrared (FTIR) spectroscopy. Quantitative analysis was performed to reveal the appearance of ion pairs and interactions between the salt and the ethylene oxide moieties with increasing salt concentration. FTIR peaks associated with polymer functional groups were found to be more useful than those of the TFSI anion for understanding the chemical state of the block copolymer electrolyte. In particular, PS peaks were used to quantify polymer dilution upon salt addition and verify that the Beer-Lambert law was valid at all concentrations investigated. PEO peaks revealed conformational changes of the polymer upon coordination with lithium ions. A previously unidentified FTIR peak was discovered that relates to polymer-salt interaction. It was used to determine the extent of salt dissociation, which compares well with a Raman study of a homopolymer electrolyte. This work definitively shows that LiTFSI dissolves into the PEO phase of the block copolymer,

\footnotetext{
Abbreviations: ATR, attenuated total reflectance; DFT, density functional theory; EO, ethylene oxide; FTIR, Fourier transform infrared spectroscopy; IR, infrared; LiTf, lithium trifluoromethanesulfonate; LiTFSI, lithium bis(trifluoromethanesulfonyl) imide; NaTf, sodium triflate; NBO, natural bond orbital; NMP, n-methyl-2-pyrrolidone; $\mathrm{MCT}$, mercury-cadmium-telluride; MD, molecular dynamics; PDI, polydispersity index; PEO, poly(ethylene oxide); PMMA, poly(methyl methacrylate); PPO, poly(propylene oxide); PS, polystyrene; PVP, poly(vinylpyrrolidone); S, styrene; SEO, polystyrene-poly(ethylene oxide) diblock copolymer; TFSI, bis(trifluoromethanesulfonyl)imide; $A$, absorbance; $A_{c}$, calibrated absorbance; $A_{c, n}$, normalized calibrated absorbance; $A_{n}$, normalized absorbance; $c$, speed of light; $c_{i}$, molarity of species $i(\mathrm{~mol} / \mathrm{L}) ; \mathrm{C} 1$, cis conformation; $\mathrm{C} 2$, trans conformation; $E_{b}$, energy of the background; $E_{s}$, energy of the sample; $M$, molecular weight $(\mathrm{g} / \mathrm{mol}) ; m$, molality $(\mathrm{mol} / \mathrm{kg}) ; m_{i}$, mass of an atom, $i$; $r$ molar ratio of lithium ion to ethylene oxide monomer; $V_{i}$, volume of species $i(\mathrm{~L}) ; x_{i}$, moles of species $i$ (mol); $\delta$, scissoring; $\kappa$, force constant; $\mu$, reduced mass of atoms, $\frac{m_{1} m_{2}}{m_{1}+m_{2}} ; v$, stretching; $\nu$, vibrational frequency $\left(\mathrm{cm}^{-1}\right), \rho_{i}$, density of species $i\left(\mathrm{~g} / \mathrm{cm}^{3}\right), \rho$, rocking; $\phi_{i}$, volume fraction of species $i ; \tau$, twisting; $\omega$, wagging.
} 
essentially unaffected by PS presence. It also establishes FTIR as a useful technique for quantifying dissociation state of concentrated polymer and composite electrolytes for lithium batteries.

Keywords: polymer electrolytes, Fourier transform infrared spectroscopy, block copolymer, composite electrolytes, solid electrolytes

\section{INTRODUCTION}

The development of future energy storage systems should include the improvement of battery materials to have higher power and higher energy density with low cost and safety (Goodenough et al., 2007; Li et al., 2018). All-solid-state batteries are a promising battery type in terms of safety, stability and energy density (Hallinan et al., 2018; Judez et al., 2018). Polymer electrolytes are important materials in manufacture of allsolid-state batteries due to their adhesivity, processability, and chemical resistance (Ruck et al., 2019). For these reasons, they will likely play a role in composite/hybrid electrolytes, considered necessary to enable future energy storage systems.

After it had been found that the ether groups in the amorphous phase of poly(ethylene oxide) (PEO) coordinate with cations and conduct ions by segmental motion (Wright, 1975; Borodin and Smith, 2006), there have been a great number of studies on the electrochemical properties and the transport mechanisms of polymer electrolyte systems. This is, in part, because practical batteries require higher charge/ discharge rate than is currently achievable with PEO-based electrolytes (Hallinan and Balsara, 2013). There are two complementary approaches that could address transport limitations: (1) the use of composites, and (2) the use of concentrated polymer electrolyte. Ion transport experiments and theory are significantly more complicated in composite and concentrated systems (Pesko et al., 2017; Villaluenga et al., 2018). Furthermore, salt concentration impacts not only polymer morphology and dynamics (Chintapalli et al., 2016; Oparaji et al., 2018) but also transport (Berliner et al., 2019; Kim and Hallinan, 2020). Increasing lithium salt concentration provides an increasing number of charge carriers in the form of dissociated ions. However, strong polymer-cation interactions can negatively impact ionic mobility (Suo et al., 2016; Ford et al., 2020). In addition, salt dissociation appears to decrease with increasing salt concentration in polymer electrolyte, resulting in the formation of triplets or higher ion clusters (Suo et al., 2016). These large agglomerates and neutral ion pairs negatively impact the diffusion and migration of the ions, making estimation or analysis of transport behavior complex or even impossible without direct knowledge of thermodynamics (via dissociation and interaction of ions with the chemical environment). This motivates an in-depth study of lithium salt dissociation and ion interaction with the chemical environment in concentrated composite electrolytes, such as block copolymer/salt mixtures.

The dissociation of $\mathrm{N}\left(\mathrm{SO}_{2} \mathrm{CF}_{3}\right)_{2}$ (bis(trifluoromethanesulfonyl) imide, TFSI) salts with group 2 elements $(\mathrm{Mg}, \mathrm{Ca}, \mathrm{Sr}$ and $\mathrm{Ba})$ in $\mathrm{PEO}$ electrolyte was studied using Fourier transform infrared spectroscopy (FTIR) by Bakker et al. (Bakker et al., 1995). Two different geometric structures of ion pairs were found for different metal ions and ion pairs were found at high salt concentration. Dissanayake et al. studied the effect of temperature on the dissociation and phase transition of $\mathrm{PEO} / \mathrm{LiSO}_{3} \mathrm{CF}_{3}$ (lithium trifluoromethanesulfonate, LiTf) electrolyte using FTIR (Dissanayake and Frech, 1995). The degree of dissociation was measured by the band intensities of $\mathrm{SO}_{3}$ and $\mathrm{CF}_{3}$ groups in associated or free ions. FTIR and Raman spectroscopy of PEO/ $\mathrm{LiN}\left(\mathrm{SO}_{2} \mathrm{CF}_{3}\right)_{2}$ (lithium bis(trifluoromethanesulfonyl)imide, LiTFSI) were performed by Rey et al. (1998b). Attempts to reveal the conformational changes of ether groups or TFSI anions, and ionpairing effects of $\mathrm{Li}^{+}$and $\mathrm{TFSI}^{-}$were carried out with limited quantitative analysis. FTIR studies of ion pairs and polymercation interactions in block copolymer electrolyte systems with lithium salts have been conducted for PEO-poly(propylene oxide)-PEO triblock copolymer with imide salts (Bakker et al., 1996), poly(vinylpyrrolidone-co-methyl methacrylate) (PVP$\mathrm{PMMA} / \mathrm{LiClO}_{4}$ (Chiu et al., 2007), and PEO-containing polyester copolymer with sodium salts (Lu et al., 2009). In this study, LiTFSI dissociation is investigated in a high molecular weight polystyrene-poly(ethylene oxide) (SEO) block copolymer which is highly promising for lithium batteries due to its superior dendrite suppression and mechanical strength derived from the presence of the glassy PS block (Stone et al., 2012; Hallinan et al., 2013; Oparaji et al., 2018).

A recent molecular dynamics (MD) study on ion solvation found a decrease in the diffusion coefficient with increasing ion concentration in a diblock copolymer (Seo et al., 2019). In our previous study, the mutual diffusion coefficient of LiTFSI in SEO block copolymer was studied using time-resolved FTIR (Kim and Hallinan, 2020). The diffusion coefficient in the low salt concentration regime was found to decrease followed by an increase of the diffusion coefficient in the high salt concentration regime, where salt dissociation is presumed to be limited. Changes of the FTIR spectra were observed at various salt concentrations that appeared to indicate the presence of associated ion pairs in the concentrated polymer electrolyte samples. This current study takes a systematic, detailed look at the equilibrium FTIR spectra of SEO/LiTFSI electrolytes in an attempt to provide better understanding of the dissociation state of the salt and the coordination between the ions and the polymer backbone. All the regions of the mid-infrared region of the spectrum have been analyzed, including peak deconvolution where necessary, to track changes in peak intensity and position. A discussion, in light of other studies in the literature, connects these observations to the chemical interactions underlying the spectral changes. 
TABLE 1 | Molar ratios $(r)$, volume fractions $\left(\phi_{i}\right)$, molarity $(c)$ and molality $(m)$ of SEO/LiTFSI mixtures.

\begin{tabular}{|c|c|c|c|c|c|c|c|}
\hline Variable & $i$ & 1 & 2 & 3 & 4 & 5 & 6 \\
\hline$r$ & & 0 & 0.02 & 0.05 & 0.085 & 0.125 & 0.17 \\
\hline \multirow[t]{3}{*}{$\phi_{i}$} & LiTFSI & 0 & 0.06 & 0.13 & 0.20 & 0.27 & 0.33 \\
\hline & EO & 0.56 & 0.53 & 0.49 & 0.45 & 0.41 & 0.38 \\
\hline & Styrene & 0.44 & 0.41 & 0.38 & 0.35 & 0.32 & 0.29 \\
\hline \multirow[t]{3}{*}{$c(\mathrm{~mol} / \mathrm{L})$} & LiTFSI & 0 & 0.26 & 0.59 & 0.92 & 1.24 & 1.54 \\
\hline & EO & 13.52 & 12.77 & 11.80 & 10.83 & 9.91 & 9.04 \\
\hline & Styrene & 4.23 & 4.00 & 3.69 & 3.39 & 3.10 & 2.83 \\
\hline$m(\mathrm{~mol} / \mathrm{kg})$ & LiTFSI & 0 & 0.45 & 1.14 & 1.93 & 2.84 & 3.86 \\
\hline
\end{tabular}

\section{EXPERIMENTAL}

\section{Materials}

A diblock copolymer of SEO was synthesized via anionic polymerization as described elsewhere (Oparaji et al., 2016). The molecular weight of PS and PEO blocks were 121 and $165 \mathrm{~kg} / \mathrm{mol}$, respectively. The PDI was 1.11 , and the volume fraction of the PEO was 0.56 at $120^{\circ} \mathrm{C}$. The synthesized polymer was freeze-dried under vacuum and stored at $-20^{\circ} \mathrm{C}$. LiTFSI was purchased from BASF and dried under vacuum for $48 \mathrm{~h}$ at $120^{\circ} \mathrm{C}$ in an antechamber connected to an argon-filled glove box. The dried LiTFSI was transferred to the glovebox without exposure to air, and is denoted "as-received".

\section{Polymer Electrolyte Preparation}

The SEO and LiTFSI were mixed in n-methyl-2-pyrrolidone (NMP), and the mixtures were stirred overnight at $60^{\circ} \mathrm{C}$. The mixtures were cast on a hot plate covered with nickel foil, and the solvent was allowed to evaporate at $60^{\circ} \mathrm{C}$. The cast films were removed from nickel foil after $24 \mathrm{~h}$ and dried under vacuum at $90^{\circ} \mathrm{C}$ for $24 \mathrm{~h}$ in the antechamber mentioned above. The thicknesses were measured by a micrometer. The average thickness of films was $100 \pm 10 \mu \mathrm{m}$. The salt molarity in the resulting films was from 0 to $1.54 \mathrm{~mol}_{\mathrm{LiTFSI}} / \mathrm{L}_{\text {total }}(r=$ 0-0.17 $\left.\mathrm{mol}_{\text {LiTFSI }} / \mathrm{mol}_{\mathrm{EO}}\right)$. Polymer electrolyte membrane casting was performed in an argon-filled glove box with $<0.2 \mathrm{ppm}$ of oxygen and water.

The molarity of species $i, c_{i}$, for each electrolyte membrane was calculated with assumption of volume additivity of the mixture,

$$
c_{i}=\frac{x_{i}}{M_{\mathrm{EO}}\left(\frac{1}{\rho_{\mathrm{EO}}}+\frac{M_{\mathrm{PS}}}{M_{\mathrm{PEO}} \rho_{\mathrm{S}}}\right)+\frac{r M_{\mathrm{LiTFS}}}{\rho_{\text {LiTFSI }}}}
$$

where $x_{i}$ is the moles of species $i, r$ is the molar ratio of salt and ethylene oxide (EO) moieties, $M$ is the molecular weight, $\rho$ is the density, and subscripts $i$, EO, S, PEO, PS and LiTFSI are species, ethylene oxide monomer, styrene monomer, PEO, PS and LiTFSI, respectively. $x_{i}$ of the LiTFSI, EO and styrene monomers were $r, 1$, and $\frac{M_{\mathrm{EO}} M_{\mathrm{PS}}}{M_{\mathrm{PEO}} M_{\mathrm{s}}}$, respectively. Density values of $1.056 \mathrm{~g} / \mathrm{cm}^{3}$ for PEO $(500 \mathrm{~kg} / \mathrm{mol})$ and $1.009 \mathrm{~g} / \mathrm{cm}^{3}$ for PS $(110 \mathrm{~kg} / \mathrm{mol})$ at $120^{\circ} \mathrm{C}$ from reference data were used in this study (Zoller and Walsh, 1995). The density of LiTFSI at $20^{\circ} \mathrm{C}$ was taken because reference data at $120^{\circ} \mathrm{C}$ could not be found, and the temperature is much lower than the melting point of LiTFSI $\left(236^{\circ} \mathrm{C}\right)$ (Aravindan et al., 2011).
The values of $r, c$ and the volume fractions of each component are shown in Table 1. Assuming volume additivity amounts to at most 5\% error (Teran and Balsara, 2014).

\section{Fourier-Transform Infrared-Attenuated Total Reflectance (FTIR-ATR) Spectroscopy} The polymer electrolyte films were placed on a single reflection diamond ATR crystal (Golden Gate, Specac) in an argon-filled glove box and sealed by an o-ring. All spectra were the result of four scans, collected at a $4 \mathrm{~cm}^{-1}$ resolution in the range of $4,000-650 \mathrm{~cm}^{-1}$ on a PerkinElmer Frontier with a liquidnitrogen-cooled MCT detector. The background of the diamond crystal was taken immediately following each measurement after removing the sample. The absolute absorbance values reported in this work were calculated directly from the detected infrared energy transmitted through the sample at each wavenumber $\left(E_{\mathrm{s}}\right)$ and the energy of the background $\left(E_{\mathrm{b}}\right)$ according to

$$
A=-\log \left(E_{\mathrm{s}} / E_{\mathrm{b}}\right) \text {. }
$$

\section{Density Functional Theory Simulation}

The interactions between the lithium cation and polymer or TFSI anion were simulated using density functional theory (DFT). All optimization and frequency calculations were conducted using the Kohn-Sham formulation of DFT with the B3LYP function and the $6-31++G(d, p)$ basis set. All geometry optimizations and vibration analyses were calculated using Gaussian 09 software (Frisch et al., 2009). All structures were optimized and frequency calculations were performed in order to ensure that a local minimum energy structure had been found. The data for the IR spectra was extracted from the output files using GaussView 5.0.9 (GaussView, 2009) and plotted using a scaling factor of 0.964 (Johnson III, 2019). Natural bond orbital (NBO) calculations were conducted on the optimized structures using NBO Version 3.1 (Glendening et al., 1998). Three-dimensional structures were produced with CYLView 1.0.1 (Legault, 2009). The chemical structures and the coordination of the materials and the simulation results are given in the Supplementary Material.

\section{RESULTS}

The FTIR spectra of pure LiTFSI and SEO/LiTFSI polymer electrolytes of different concentrations at $120^{\circ} \mathrm{C}$ are shown in Figure 1. The assignment of peaks of pure materials is shown in Table 2. The characteristic peaks of LiTFSI and PEO in the SEO electrolyte shifted with respect to the pure components, indicating that the salt dissolved into the PEO phase of SEO. The PS peaks do not exhibit any changes in peak position because the PS component is not involved in solvation of the salt. Therefore, all changes of the IR bands of LiTFSI arise from the interaction only between the PEO and LiTFSI. The shift of the peaks with addition of salt is presented in Table 2, where peak locations are reported for all salt concentrations investigated.

The increase of lithium salt concentration resulted in the increase of the absorbance of the peaks associated with LiTFSI. 


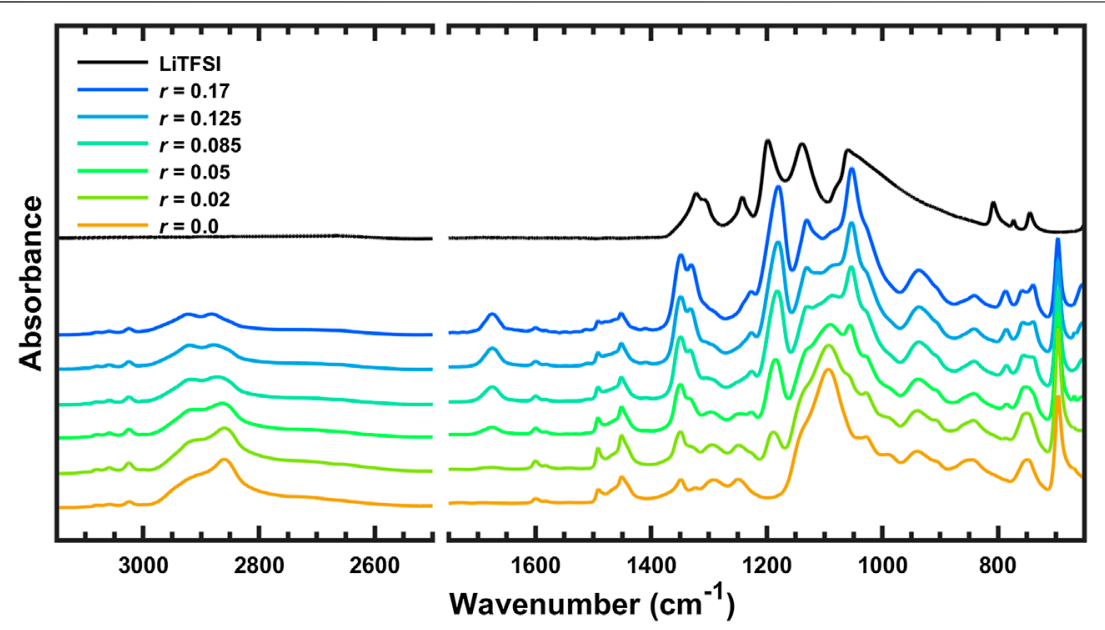

FIGURE 1 | FTIR spectra of SEO, LiTFSI, and SEO/LiTFSI polymer electrolytes with different salt concentrations at $120^{\circ} \mathrm{C}$. For clarity, spectra have been vertically shifted, and regions that are not of interest have been omitted: 4,000-3,150 and 2,500-1,750 $\mathrm{cm}^{-1}$.

TABLE 2 | FTIR peak assignments of SEO, LiTFSI and SEO/LiTFSI polymer electrolytes and peak shifts at various salt concentrations.

\begin{tabular}{|c|c|c|c|c|c|c|c|c|c|}
\hline \multicolumn{3}{|c|}{ Vibration assignment } & \multirow[t]{2}{*}{ SEO } & \multicolumn{5}{|c|}{ SEO/LiTFSI } & \multirow[t]{2}{*}{ LiTFS। } \\
\hline PS & PEO & LiTFSI & & 0.02 & 0.05 & 0.085 & 0.125 & 0.17 & \\
\hline Phenyl group & & & & & 3,101 & 3,101 & 3,100 & 3,102 & \\
\hline Phenyl group & & & 3,080 & 3,081 & 3,080 & 3,080 & 3,080 & 3,080 & \\
\hline Phenyl group & & & 3,059 & 3,059 & 3,059 & 3,059 & 3,059 & 3,059 & \\
\hline Phenyl group & & & 3,025 & 3,025 & 3,025 & 3,025 & 3,024 & 3,025 & \\
\hline Phenyl group & & & 2,999 & 3,001 & 3,000 & 2,997 & $3,000(w)$ & $3,000(w)$ & \\
\hline$v_{\mathrm{a}} \mathrm{CH}_{2}$ & $v_{\mathrm{a}} \mathrm{CH}_{2}$ & & 2,925 & 2,924 & 2,924 & 2,924 & 2,925 & 2,925 & \\
\hline$v_{\mathrm{s}} \mathrm{CH}$ & $v_{\mathrm{s}} \mathrm{CH}_{2}$ & & 2,860 & 2,860 & 2,864 & 2,873 & 2,878 & 2,882 & \\
\hline Phenyl group & & & 1,600 & 1,600 & 1,600 & 1,600 & 1,600 & 1,600 & \\
\hline Phenyl group & $\delta \mathrm{CH}_{2}$ & & 1,491 & 1,492 & 1,492 & 1,492 & 1,492 & 1,492 & \\
\hline \multirow[t]{12}{*}{$\delta \mathrm{CH}_{2}+$ phenyl group } & $\mathrm{CH}_{2}$ & & 1,451 & 1,451 & 1,451 & 1,451 & 1,452 & 1,452 & \\
\hline & $\mathrm{CH}_{2}$ & $v_{a} \mathrm{SO}_{2}$ & 1,349 & 1,349 & 1,349 & 1,349 & 1,349 & 1,348 & 1,332 \\
\hline & & $v_{a} \mathrm{SO}_{2}$ & & 1,333 & 1,334 & 1,333 & 1,332 & 1,331 & 1,309 \\
\hline & $\omega \mathrm{CH}_{2}$ & & 1,324 & 1,325 & & & & & \\
\hline & $\tau \mathrm{CH}_{2}$ & & 1,292 & 1,294 & 1,297 & 1,305 & 1,308 & 1,309 & \\
\hline & $\tau \mathrm{CH}_{2}$ & & 1,249 & 1,249 & 1,247 & & & & \\
\hline & & $v_{s} \mathrm{CF}_{3}$ & & 1,225 & 1,226 & 1,226 & 1,226 & 1,227 & 1,242 \\
\hline & & $v_{a} \mathrm{CF}_{3}$ & & 1,189 & 1,185 & 1,181 & 1,180 & 1,180 & 1,198 \\
\hline & $\nu \operatorname{COC}(\mathrm{w})$ & & $1,145(w)$ & & & & & & \\
\hline & & $v_{\mathrm{S}} \mathrm{SO}_{2}$ & & 1,133 & 1,130 & 1,130 & 1,131 & 1,131 & 1,139 \\
\hline & $v \mathrm{COC}$ & & 1,093 & 1,093 & 1,090 & 1,086 & 1,085 & 1,088 & \\
\hline & & $v_{a} \mathrm{SNS}$ & & & 1,056 & 1,054 & 1,053 & 1,053 & 1,060 \\
\hline \multirow[t]{3}{*}{ Phenyl group } & $\mathrm{C}-\mathrm{C}-\mathrm{O}-\mathrm{C}-\mathrm{C}$ deformation & & $1,028(w)$ & 1,028 & 1,029 & 1,029 & 1,028 & 1,027 & \\
\hline & $v \mathrm{COCCH}_{2}$ & & 990 & 989 & 990 & & & & \\
\hline & $\rho \mathrm{CH}_{2}$ & & 940 & 940 & 938 & 937 & 937 & 937 & \\
\hline \multirow[t]{5}{*}{ Phenyl group } & $\rho \mathrm{CH}_{2}(\mathrm{~W})$ & & $906(w)$ & $908(w)$ & $906(w)$ & & & & \\
\hline & $\rho \mathrm{CH}_{2}$ and deformation & & $856(w)$ & 859(w) & & & & & \\
\hline & $\rho \mathrm{CH}_{2}$ and deformation & & 845 & 843 & 842 & 841 & 841 & 841 & \\
\hline & & $v \mathrm{CS}, v \mathrm{SN}, v \mathrm{CF}_{3}$ & & 786 & 785 & 785 & 786 & 787 & 808 \\
\hline & & $v \mathrm{CS}, \nu \mathrm{SN}, \delta \mathrm{CF}_{3}$ & & 754 & 754 & 759 & 759 & 759 & 773 \\
\hline \multirow[t]{2}{*}{ Phenyl group } & & & 748 & 748 & 747 & & & & \\
\hline & & $v_{S} \mathrm{SNS}$ & & 747 & 737 & 737 & 739 & 739 & 745 \\
\hline$\rho \mathrm{CH}_{2}$ & & & 696 & 696 & 696 & 696 & 696 & 696 & \\
\hline
\end{tabular}

w: weak, $v$ : stretching, $\delta$ : scissoring, $\rho$ : rocking, $\omega$ : wagging, subscript a: asymmetric, s: symmetric. 
The most obvious increases can be found for the $\mathrm{SO}_{2}$ asymmetric vibration $\left(v_{\mathrm{a}} \mathrm{SO}_{2}, 1,349\right.$ and $\left.1,330 \mathrm{~cm}^{-1}\right), \mathrm{CF}_{3}$ asymmetric vibration $\left(v_{\mathrm{a}} \mathrm{CF}_{3}, 1,180 \mathrm{~cm}^{-1}\right)$, and SNS asymmetric vibration ( $v_{\mathrm{a}}$ SNS, $1,053 \mathrm{~cm}^{-1}$ ). Conversely, the absorbance of peaks associated with PEO and PS decreased with increasing salt concentration. Decreasing $\mathrm{CH}$ or $\mathrm{CH}_{2}$ stretching bands were observed with increasing salt concentration at high wavenumber $(\mathrm{vCH}$ of benzene rings, $3,100-3,000 \mathrm{~cm}^{-1}$, and $\nu \mathrm{CH}$ and $\nu \mathrm{CH}_{2}$ of PS and PEO backbone, 2,925 and $2,860 \mathrm{~cm}^{-1}$ ). The COC vibration of PEO ( $\nu \mathrm{COC}, 1,093 \mathrm{~cm}^{-1}$ ) was found to have decreased and shifted by addition of lithium salt. The various infrared bands associated with the phenyl groups of PS showed decreasing absorbance with increasing salt concentration, but did not show any change in the peak position. Since some peaks shifted as a function of salt concentration, to avoid confusion the peaks of the salt components are referred to by their location in the polymer/salt system with the highest salt concentration in our experiments ( $\left.r=0.17 \mathrm{~mol}_{\mathrm{LiTFSI}} / \mathrm{mol}_{\mathrm{EO}}\right)$, and the peaks of the polymer components are referred to by their location in pure SEO ( $\left.r=0 \mathrm{~mol}_{\text {LiTFSI }} / \mathrm{mol}_{\mathrm{EO}}\right)$. Refer to Table 2 for detailed information regarding peak shifting according to the FTIRATR spectra before deconvolution.

The left-hand side of Figure $\mathbf{1}$ is the FTIR-ATR spectra of the polymer electrolytes between 3,150 and $2,500 \mathrm{~cm}^{-1}$. In this wavenumber range, there are no LiTFSI peaks, and IR bands in this range are due to carbon-hydrogen vibrations of PS or PEO. The small peaks above $3,000 \mathrm{~cm}^{-1}$ are $\mathrm{CH}$ stretching of the phenyl groups (Jabbari and Peppas, 1993). These bands have small changes in intensity with increasing salt concentration, but the peak positions are constant. The broad set of convoluted bands between 3,000 and $2,500 \mathrm{~cm}^{-1}$ are due to $\mathrm{CH}_{2}$ stretching of $\mathrm{PS}$ and $\mathrm{PEO}, \mathrm{CH}$ stretching of the main chain of PS, and aromatic ring vibrations (Jabbari and Peppas, 1993). Although the highest peak at $2,859 \mathrm{~cm}^{-1}$ has components of PS and PEO, it seems to be dominated by the signal from $\mathrm{CH}_{2}$ of PEO since the peak shifts with salt addition. The peaks in this region from the backbone of the PS block seem to have only a slight decrease with increasing salt concentration and no change in position and shape, because the PS component is inert to the interaction with the lithium salt (Oparaji, 2017). The changes in the absorbance of PS peaks are thought to be due to dilution by addition of LiTFSI, which increases the volume fraction of the PEO/LiTFSI phase. The depth of penetration of the FTIR-ATR evanescent wave is on the order of $1 \mu \mathrm{m}$ and the infrared spot size is on the order of $1 \mathrm{~mm}^{2}$. Thus, this technique samples a volume on the order of $1 \mathrm{~nL}=$ $(100 \mu \mathrm{m})^{3}$, which is a sufficiently large control volume that the continuum concentration of the polymer electrolyte should be considered, unaffected by the block copolymer nanostructure, which is on the order of $100 \mathrm{~nm}$. Therefore, addition of LiTFSI into the PEO phase of the block copolymer not only decreases the concentration of PEO, but also decreases the effective, macroscopic concentration of PS. Intensity changes of peaks associated with SEO are examined quantitatively and in more detail below using more intense peaks that occur in the fingerprint region. The right-hand side of Figure $\mathbf{1}$ is the fingerprint region from 1,750 to $650 \mathrm{~cm}^{-1}$. The IR spectra of the polymer electrolytes in this region will be discussed subsequently using Figures 2-9, which present enlarged sections with more detail.

\section{DISCUSSION}

The results were examined thoroughly in terms of salt dissociation and ion interaction because the degree of dissociation and ion interaction largely impact the polymer electrolytes' physical and electrochemical properties such as the structure, mechanical strength, or ionic conductivity. The mechanical properties of block copolymer electrolytes are known to be dependent on the volume fraction of each component (Niitani et al., 2005; Devaux et al., 2015), the microphase separation (Rosedale and Bates, 1990; Ruzette et al., 2001), and the sequence of blocks (Matsuo et al., 1968). Since microphase separation of SEO becomes stronger with increasing salt content due to strong ionic interactions of lithium salt in PEO phase (Metwalli et al., 2015; Chintapalli et al., 2016; Oparaji et al., 2018), the mechanical strength of PS-PEO-based block copolymer electrolytes that are microphase separated in the neat state merely depends on the molecular weight and the volume fraction of glassy phase (Devaux et al., 2015; Oparaji et al., 2018).

The polymer-salt interaction of PEO-based polymer electrolytes was related to the thermodynamic and electrochemical properties using Lewis-base approach by Wieczorek et al. (Wieczorek et al., 1995). Different types of fillers (polymeric, organic, or inorganic) acted as Lewis acid or base centers and caused non-uniform distribution of metal cations in the vicinity of the fillers forming different types of complexes. This caused unique features of the polymer composites with each filler in terms of the crystallinity, the glass transition temperature, and the dependence of ionic conductivity on temperature or filler concentration. Pesko et al. (2016) studied the electrochemical, thermodynamic, and structural properties as a function of solvation-site connectivity which is defined as the ratio of number of oxygen atoms to the total number of atoms in a repeat unit. The solvation-site connectivity was controlled by varying the chain lengths of vinyl or EO groups in the repeat unit. Higher connectivity makes more solvation-sites and narrows the distance between solvation-sites, which facilitates ion hopping between the solvation-sites. Ionic conductivity showed a linear increase to increasing number of solvation-sites for $0.06 \leq r \leq 0.14$ and $T_{g}+$ $55^{\circ} \mathrm{C} \leq T \leq T_{g}+95^{\circ} \mathrm{C}$. A recent study of PEO-based polymer electrolytes with sodium triflate $(\mathrm{NaTf})$ showed a rapid decrease of ionic conductivity at high salt concentration $\left(\mathrm{EO}: \mathrm{Na}^{+} \leq 8\right)$ where appearance of aggregates was observed by FTIR spectroscopy (Lehmann et al., 2019). In block copolymer electrolytes, strong interaction of lithium salts with conductive polymer induces strong microphase separation and uniform distribution of salt in the conductive phase leading to improved ion transport (Seo et al., 2019). The interaction of both cations and anions with the non-conductive phase reduces the ion transport (Jo et al., 2013; Seo et al., 2019). 

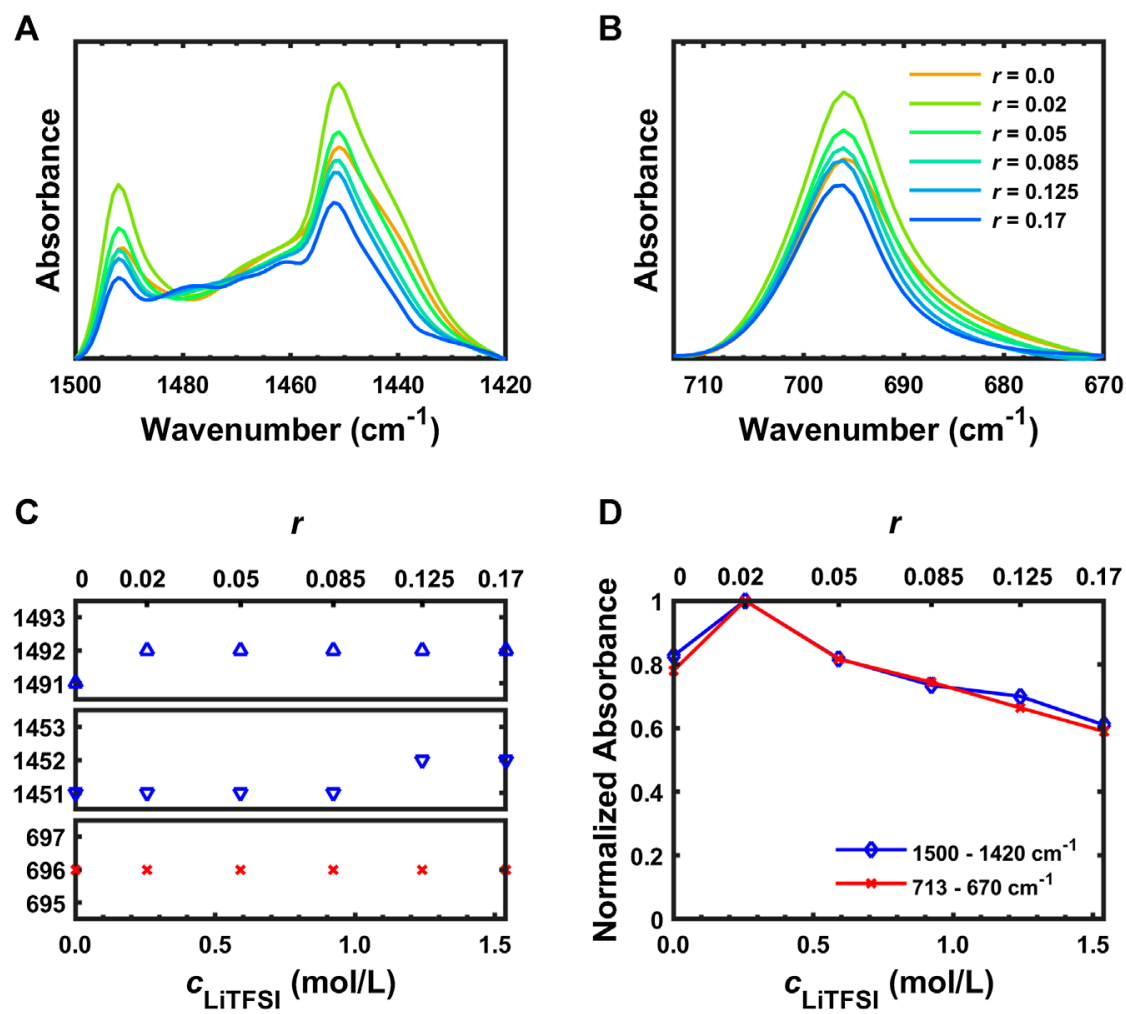

FIGURE 2 | (A) FTIR-ATR spectra of SEO/LiTFSI between 1,500 and 1,420 $\mathrm{cm}^{-1}$, (B) FTIR-ATR spectra of SEO/LiTFSI between 713 and $670 \mathrm{~cm}^{-1}$, (C) peak positions of $\delta \mathrm{CH}_{2}+$ phenyl group and $\rho \mathrm{CH}_{2}$, and (D) normalized integrations of (A) and (B).

Since ions play an important part in battery electrolytes, there are quite a few studies of the dissociation state of alkali salts in various solvents. For example, the solvation and ionic state of LiTFSI can be investigated using the spectroscopic behavior of the block copolymer electrolytes. Vibrational spectroscopies are powerful methods to study the state of ions or molecules influenced by intermolecular or intramolecular interactions. Although its specialty is for identification of compounds, detection of functional groups, and qualitative analysis of chemical interactions, quantitative analysis is also possible. This requires precise and careful control of samples and experimental conditions along with appropriate analysis and proper assumptions (Kakihana et al., 1990; Fieldson and Barbari, 1993; Ferry et al., 1995; Sammon et al., 1998; Elabd et al., 2003; Philippe et al., 2004; Hallinan and Elabd, 2007; Oparaji et al., 2016; Yang et al., 2018; Kim and Hallinan, 2020). In this section, the dissociation of LiTFSI in SEO is investigated via detailed analysis of the fingerprint region.

Absorbance of FTIR is proportional to concentration according to the Beer-Lambert law; appropriate concentration units are molarity ( $\mathrm{M}$ or $\mathrm{mol} / \mathrm{L}$ ). The molarity (and therefore absorbance) of the polymer is expected to decrease with increasing salt content. Pure SEO peaks $\left(\delta \mathrm{CH}_{2}+\right.$ phenyl group, 1,491 and $\left.1,451 \mathrm{~cm}^{-1}\right)$ as well as pure PS peak $\left(\rho \mathrm{CH}_{2}, 696 \mathrm{~cm}^{-1}\right)$ were chosen to study the dilution of SEO by addition of LiTFSI. These are strong polymer peaks without any overlap by LiTFSI peaks. They are shown in Figures 2A,B. The peak positions do not show any significant change as shown in Figure 2C. However, the absorbance of these peaks increased when salt was first introduced $(r=0.02)$ then steadily decreased with increasing salt concentration as shown in Figure 2D. The initial increase of the IR absorbance at low salt concentration $(r=0.02)$ can be explained by (1) the density change of polymer/salt mixture due to non-ideal mixing (Teran and Balsara, 2014) or (2) the change of chemical environment of the system by addition of salt influencing the molar extinction coefficient which affects the IR intensity (Lappi et al., 2004). The further decrease of absorbance with increasing LiTFSI concentration is due to dilution as mentioned above.

Figure $\mathbf{3 A}$ shows the FTIR-ATR spectra of SEO/LiTFSI between 1,400 and $1,150 \mathrm{~cm}^{-1}$. The $v_{\mathrm{a}} \mathrm{SO}_{2}$ appears as a doublet at 1,348 and $1,331 \mathrm{~cm}^{-1}$. The intensity of the doublet increases with increasing salt concentration. This doublet was found at lower frequencies for pure LiTFSI, 1,332 and $1,309 \mathrm{~cm}^{-1}$ (Table 2). The position of the lower wavenumber peak appears to have a slight blueshift as salt concentration is increased from $r=0$ to $r=0.05$ and then a slightly more significant redshift from $r=0.085$ to $r=0.17$. This qualitatively tracks the trend of ionic conductivity of these electrolytes which increases to a maximum in the vicinity of $r=0.085$, followed by decreasing conductivity at yet higher salt concentration (Panday et al., 2009; Majeed, 2019). Unfortunately, the change in peak location is too small (less than the resolution of the measurement) for quantitative analysis. This doublet is interesting because of the unique behavior compared to the other 


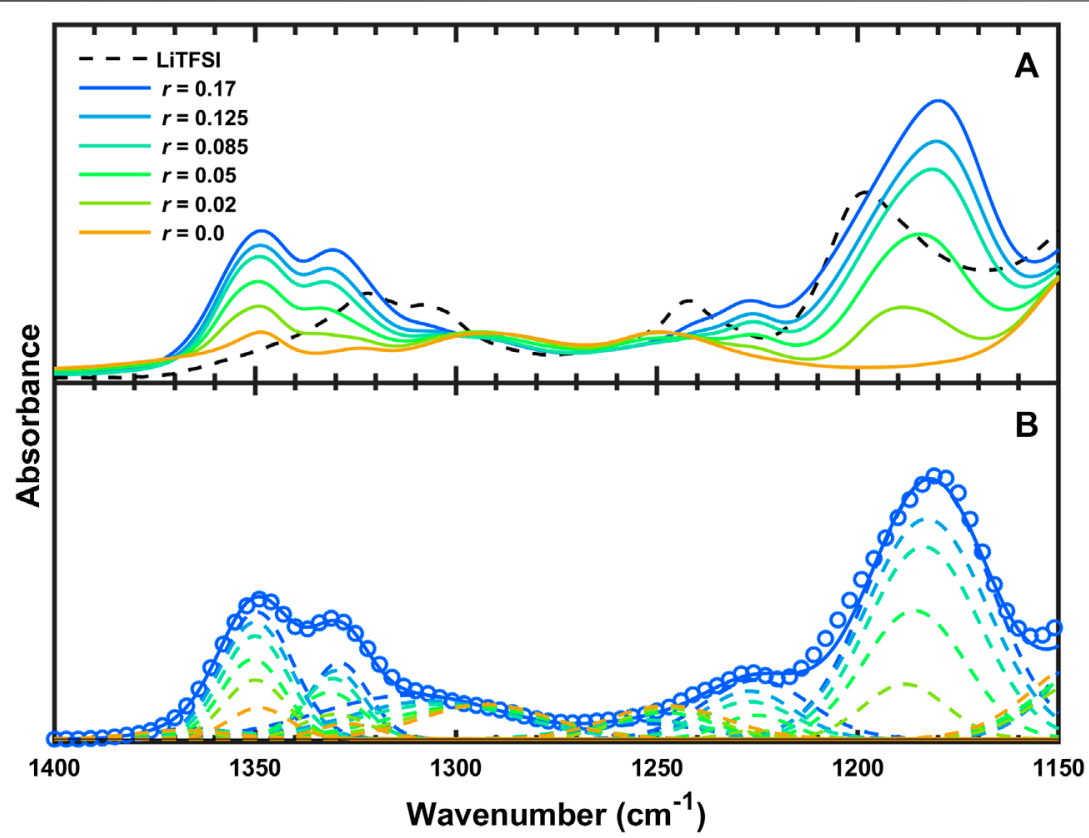

FIGURE 3 | (A) FTIR-ATR spectra and of SEO, LiTFSI, and SEO/LiTFSI from 1,400 to 1,150 $\mathrm{cm}^{-1}$ and (B) experimental data (circles) and fit (solid curve) of SEO/ LiTFSI $(r=0.17)$ as well as deconvoluted peaks (dashed curves) of SEO/LiTFSI at the various salt concentrations studied.
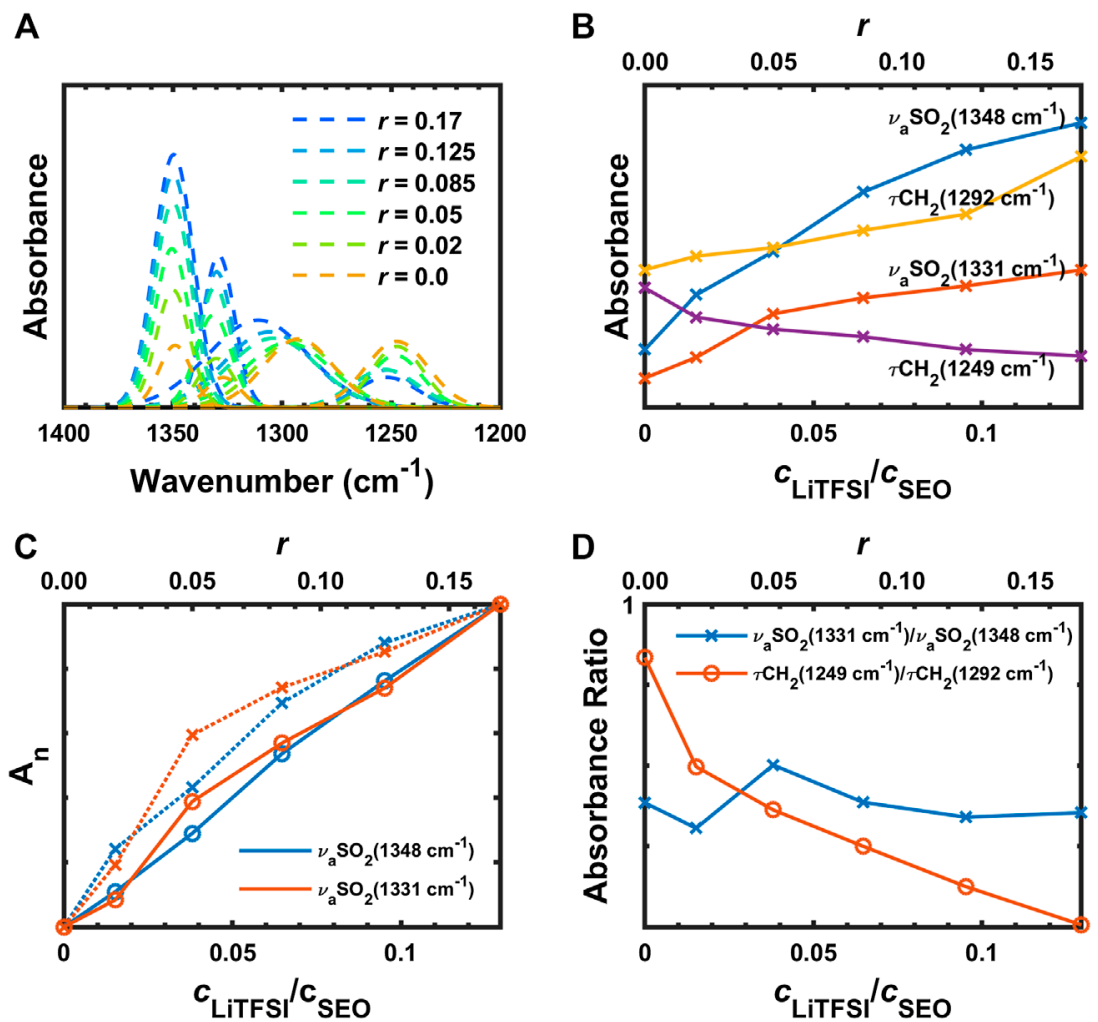

FIGURE 4 | (A) Deconvoluted peaks of IR bands from 1,400 to $1,200 \mathrm{~cm}^{-1}$, (B) absorbances of $v_{\mathrm{a}} \mathrm{SO}_{2}$ and $\tau \mathrm{CH}_{2},(\mathbf{C})$ normalized absorbances of $\nu_{\mathrm{a}} \mathrm{SO} \mathrm{H}_{2}\left[\cdots \times \cdots \mathrm{A}_{n}\right.$, $-\mathrm{O}-A_{c, n}$, blue: $v_{\mathrm{a}} \mathrm{SO}_{2}(1,348)$, red: $\left.v_{\mathrm{a}} \mathrm{SO}_{2}\left(1,331 \mathrm{~cm}^{-1}\right)\right]$, and (D) ratios of $v_{\mathrm{a}} \mathrm{SO}_{2}$ and $\tau \mathrm{CH}_{2}$ peaks. 
LiTFSI peaks. It is worth noting that the blueshift from pure LiTFSI to the SEO/LiTFSI polymer electrolyte (i.e., the peak shift to higher frequency by dissolving LiTFSI in polymer) only occurs for this doublet. The other LiTFSI peaks in the polymer electrolyte are redshifted with respect to pure LiTFSI (in the infrared range in this study). The ratio of the two peaks in the doublet has been used as an indication of the presence of conformational isomers of TFSI anions (Rey et al., 1998b). However, the peaks at 1,348 and $1,331 \mathrm{~cm}^{-1}$ overlap with the symmetric and asymmetric $\mathrm{CH}_{2}$ wagging $\left(\omega_{\mathrm{s}} \mathrm{CH}_{2}, 1,348 \mathrm{~cm}^{-1}\right.$, $\left.\omega_{\mathrm{a}} \mathrm{CH}_{2}, 1,324 \mathrm{~cm}^{-1}\right)$ making quantitative analysis ambiguous and suspicious. The most intense peak in this region is the asymmetric $\mathrm{CF}_{3}$ stretching of the TFSI anion $\left(v_{\mathrm{a}} \mathrm{CF}_{3}\right)$. The symmetric vibration of this functional group $\left(v_{\mathrm{s}} \mathrm{CF}_{3}\right)$ appears as a shoulder on the high wavenumber side. The symmetric $\mathrm{CF}_{3}$ vibration is hard to notice at lower salt concentrations because it overlaps with the $\mathrm{CH}_{2}$ twisting band $\left({ }_{\tau} \mathrm{CH}_{2}, 1,249 \mathrm{~cm}^{-1}\right)$ and it is much smaller than $v_{\mathrm{a}} \mathrm{CF}_{3}$. Like the $\mathrm{SO}_{2}$ stretching peaks, the intensity of the $\mathrm{CF}_{3}$ peaks increase with increasing salt concentration. Unlike the $\mathrm{SO}_{2}$ vibrations, the $\mathrm{CF}_{3}$ stretching peaks are located at lower frequency than those of pure LiTFSI. Regarding the weak SEO peaks, above a salt concentration of $r=0.085$, the ${ }_{\tau} \mathrm{CH}_{2}$ at $1,249 \mathrm{~cm}^{-1}$ appears as a shoulder on the $v_{s} \mathrm{CF}_{3}$ peak. The same behavior is apparent for the other twisting $\mathrm{CH}_{2}$ peak at $1294 \mathrm{~cm}^{-1}$ near the $v_{\mathrm{a}} \mathrm{SO}_{2}\left(1,330 \mathrm{~cm}^{-1}\right)$ peak. Figure 3B demonstrates that a deconvolution into six peaks fits this region of the spectrum quite well.

The deconvoluted IR bands from Figure $\mathbf{3 B}$ in the region from 1,400 to $1,200 \mathrm{~cm}^{-1}$ are presented in Figure $4 \mathrm{~A}$. With increasing salt concentration, the deconvoluted $v_{\mathrm{a}} \mathrm{SO}_{2}$ peaks at 1,348 and $1,331 \mathrm{~cm}^{-1}$ do not significantly change position but they do increase with increasing salt concentration (Figure 4B) as expected. This is shown quantitatively in Figure 4C, where the normalized integrated absorbance of the deconvoluted $v_{\mathrm{a}} \mathrm{SO}_{2}$ peaks increase monotonically with $r$. The peak at $1,348 \mathrm{~cm}^{-1}$ is known to be affected more by $\mathrm{C} 1$ conformer (cis) than C2 (trans), and vice versa for the other (Herstedt et al., 2005). The ratio of these peaks therefore have been shown to be different with different content of geometric isomers. However, for PEObased polymer electrolytes, as we mentioned above, the $v_{\mathrm{a}} \mathrm{SO}_{2}$ doublet overlaps with $\omega \mathrm{CH}_{2}$, such that decoupling and quantification of these peaks are very difficult. With this in mind, the ratio of the $v_{\mathrm{a}} \mathrm{SO}_{2}$ peak at $1,331 \mathrm{~cm}^{-1}$ to that at $1,348 \mathrm{~cm}^{-1}$ is shown in Figure 4D, and no significant physical implication was found in this study.

In Figure 4B, the increase of absorbance of the $v_{\mathrm{a}} \mathrm{SO}_{2}$ doublet seems to deviate from the expected linear relationship with the concentration. The peak absorbances were normalized for comparison

$$
A_{n}^{i}=\frac{A^{i}-A^{1}}{A^{6}-A^{1}}
$$

where $A_{n}$ is the normalized absorbance, $A$ is the absorbance at each salt concentration, and the superscripts denote the sample numbers in Table 1. In order to remove the effect of volume changes, the peaks were calibrated by the absorbance of $\delta \mathrm{CH}_{2}+$ phenyl group $\left(1,500-1,420 \mathrm{~cm}^{-1}\right)$.

$$
A_{c}^{i}=\frac{A^{i}}{A^{i}\left(\delta \mathrm{CH}_{2}+\text { phenyl group }\right)}
$$

where $A_{c}$ is calibrated absorbance, $A$ is the absorbance of the peak to be calibrated, and $A\left(\delta \mathrm{CH}_{2}+\right.$ phenyl group $)$ is the absorbance of $\delta \mathrm{CH}_{2}+$ phenyl group $\left(1,500-1,420 \mathrm{~cm}^{-1}\right)$.

The calibrated absorbances were then normalized

$$
A_{c, n}^{i}=\frac{A_{c}^{i}-A_{c}^{1}}{A_{c}^{6}-A_{c}^{1}}
$$

where superscripts denote the sample numbers and the subscripts $c$ and $n$ mean calibration and normalization, respectively. As shown in Figure 4C, the normalized calibrated absorbances were linear as a function of the molarity ratio of salt to SEO. The linearity of the plot demonstrates the validity of the Beer-Lambert law across the entire concentration range since $A_{\text {salt }} / A_{\mathrm{SEO}} \propto c_{\text {salt }} / c_{\mathrm{SEO}}$. Note that $c_{\mathrm{SEO}}=c_{\mathrm{EO}}+c_{S}$. The calibration and normalization process continues to be applied in the following analysis.

The $\tau \mathrm{CH}_{2}\left(1,292\right.$ and $\left.1,249 \mathrm{~cm}^{-1}\right)$ show interesting behavior in Figure 4A. These peaks initially have similar intensities and shape when there is no salt in the polymer. With addition of salt, the $\tau \mathrm{CH}_{2}$ band at $1,292 \mathrm{~cm}^{-1}$ gradually shifts to higher wavenumber and the peak area increases (Figure 4B) while the other ${ }_{\tau} \mathrm{CH}_{2}$ becomes smaller and broader. The ratio of the two $\mathrm{CH}_{2}$ bands from this study $\left[\mathrm{CH}_{2}\left(1,249 \mathrm{~cm}^{-1}\right) / \tau \mathrm{CH}_{2}\left(1,292 \mathrm{~cm}^{-1}\right)\right]$ is shown in Figure 4D. Matsuura and coworkers studied the conformational change of molten PEO and reported the gauche $\left(1,296 \mathrm{~cm}^{-1}\right)$ and gauche + trans $\left(1,246 \mathrm{~cm}^{-1}\right)$ isomerism of $\mathrm{CH}_{2}$ deformations (Matsuura and Fukuhara, 1986). Shieh and Liu identified the IR bands at 1,280 and $1,242 \mathrm{~cm}^{-1}$ as gauche and trans conformations of $\tau \mathrm{CH}_{2}$, respectively (Shieh and Liu, 2004). Therefore, in this paper we denote the band at $1,292 \mathrm{~cm}^{-1}$ for the pure SEO $(r=0)$ as gauche and $1,249 \mathrm{~cm}^{-1}$ as trans conformer. The transition from trans to gauche conformations with increasing LiTFSI content implies that there is chain reorientation due to the attractive force of the oxygen atoms in the ether groups coordinating lithium cations in a crownether-like structure. MD simulation of the gauche-trans conformations of EO chains according to coordination with hydrogen ions forming hydrogen bonds has been reported by Begum and Matsuura, and gauche conformation has been found to be most favorable (Begum and Matsuura, 1997).

The deconvoluted IR bands from Figure $3 \mathbf{B}$ at $1,227 \mathrm{~cm}^{-1}$ $\left(v_{\mathrm{s}} \mathrm{CF}_{3}\right)$ and $1,180 \mathrm{~cm}^{-1}\left(v_{\mathrm{a}} \mathrm{CF}_{3}\right)$ are presented in Figure 5A. The $v_{\mathrm{a}} \mathrm{CF}_{3}$ band arises at $1,189 \mathrm{~cm}^{-1}$ for $r=0.02$ and monotonically increases until $r=0.17$, shifting to $1,180 \mathrm{~cm}^{-1}$. It is unclear what causes the significant shift in this peak. Despite the significant number of spectroscopic studies of TFSI, there is surprisingly little discussion of this intense IR peak. This may be partially due to the large number of vibrational modes of this functional group (Herstedt et al., 2005). The significant shift of $v_{\mathrm{a}} \mathrm{CF}_{3}$ to lower wavenumber from pure LiTFSI to that in the block copolymer electrolyte and the further redshift with increasing LiTFSI concentration could be related to (1) the strong electronegativity of fluorine and the delocalized negative charge upon dissociation, (2) conformational changes of TFSI, (3) hydrophobic interactions between different $\mathrm{CF}_{3}$ groups, and/ or (4) $\mathrm{Li}^{+}-\mathrm{F}$ coordination (Arnaud et al., 1996). Due to the 
A

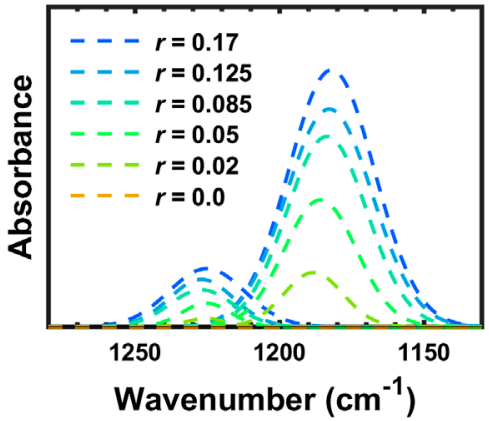

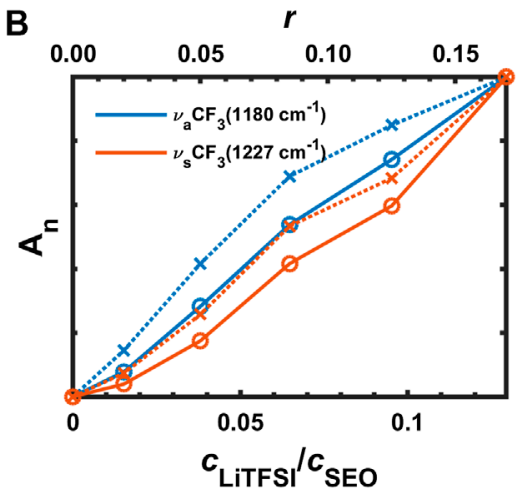

FIGURE 5 | (A) Deconvoluted FTIR-ATR bands and (B) normalized absorbances of $v_{\mathrm{S}} \mathrm{CF}_{3}$ and $v_{\mathrm{a}} \mathrm{CF}_{3}\left[\cdots \times \cdots A_{n},-\mathrm{O}-A_{c, n}\right.$, blue: $v_{\mathrm{a}} \mathrm{CF}_{3}\left(1,180 \mathrm{~cm}{ }^{-1}\right)$, red: $_{\mathrm{S}_{\mathrm{S}}} \mathrm{CF}_{3}$ $\left.\left(1,227 \mathrm{~cm}^{-1}\right)\right]$.

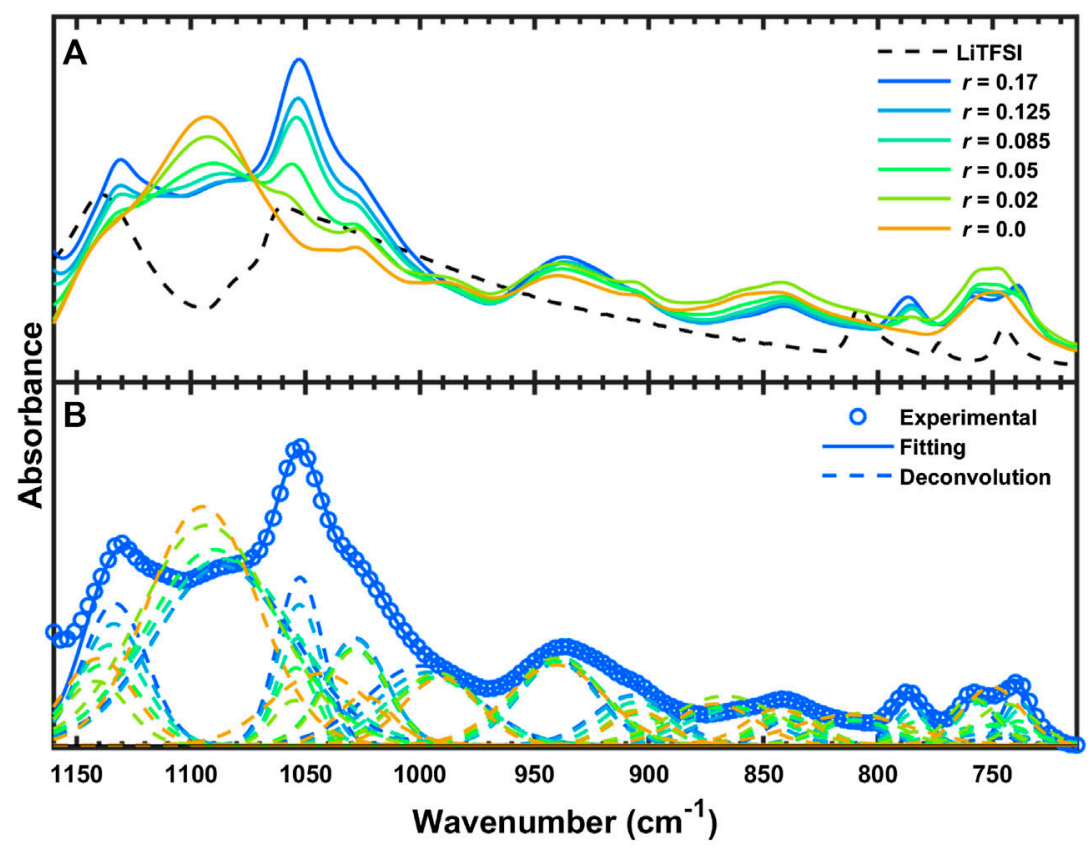

C

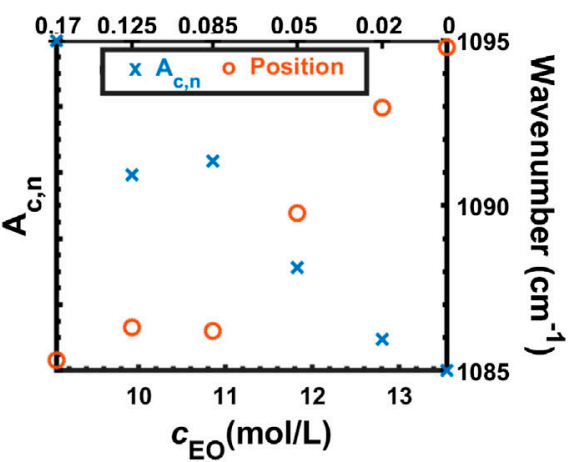

FIGURE 6 | (A) FTIR-ATR spectra of SEO, LiTFSI, and SEO/LiTFSI in the region from 1,160 to $713 \mathrm{~cm}^{-1}$, (B) deconvolution of SEO/LiTFSI, and (C) quantification of $\mathrm{COC}$ peak absorbance and position. 
uncertainty and ambiguity in assigning physical significance to the spectral changes of $v_{\mathrm{a}} \mathrm{CF}_{3}$, attention is turned to the weaker $v_{s} \mathrm{CF}_{3}$ shoulder. The absorbance of $v_{s} \mathrm{CF}_{3}$ increases with increasing salt concentration. This can be seen quantitatively in Figure 5B, where the normalized integrated absorbance of both $\mathrm{CF}_{3}$ stretching peaks is shown. The weaker normalized absorbance increase of $v_{s} \mathrm{CF}_{3}$ as compared to $v_{\mathrm{a}} \mathrm{CF}_{3}$ is most likely due to the overlap of $v_{s} \mathrm{CF}_{3}$ with $\tau \mathrm{CH}_{2}$, as mentioned above. With increasing salt concentration, the symmetric $\mathrm{CF}_{3}$ vibration appears to blueshift slightly, but again physical significance is difficult to ascribe. Based on the linearity of $A_{c, n}\left(v_{\mathrm{a}} \mathrm{CF}_{3}\right)$ in Figure $\mathbf{5 B}$, it is clear that $v_{\mathrm{a}} \mathrm{CF}_{3}$ accurately represents salt concentration, verifying it use for diffusion studies in prior work (Kim and Hallinan, 2020).

Figure 6 shows the FTIR-ATR spectra of SEO $(r=0)$, LiTFSI, and the salt-doped polymer electrolytes between 1,160 and $713 \mathrm{~cm}^{-1}$. As shown in Figure 6A, the symmetric stretching vibration of $\mathrm{SO}_{2}\left(v_{\mathrm{S}} \mathrm{SO}_{2}, 1,131 \mathrm{~cm}^{-1}\right)$ of the polymer electrolytes is found at lower wavenumber than that of the dry solid LiTFSI $\left(1,139 \mathrm{~cm}^{-1}\right)$. The other IR peak from the salt is the SNS vibration mode $\left(v_{\mathrm{a}} \mathrm{SNS}\right)$ at $1,053 \mathrm{~cm}^{-1}$. This is also found at lower position than that of pure LiTFSI $\left(1,060 \mathrm{~cm}^{-1}\right)$. The COC stretching ( $\nu$ COC, $1,093 \mathrm{~cm}^{-1}$ ) decreases and redshifts with increasing salt concentration, in agreement with other reports of PEO/salt electrolytes (Bakker et al., 1995; Bakker et al., 1996; Zhang and Wang, 2009). The ${ }$ COC is known to be related to the crystalline structure of $\mathrm{PEO}$ which appears strongly below the melting temperature $\left(T_{\mathrm{m}}\right)$ of PEO then reduces above $T_{\mathrm{m}}$ due to crystal melting. The spectra were collected at $120^{\circ} \mathrm{C}$ where there is no crystallinity in PEO. Thus, the decrease of the COC peak with increasing salt concentration is due to (1) dilution of ether groups with the addition of salt, and (2) change of COC conformation, forming crown-ether-like coordination with the lithium cations. The dilution effect is examined by calibrating and normalizing the deconvoluted COC absorbance. This is shown as a function of EO molarity in Figure 6C. At high EO molarity (i.e., low salt concentration) a linear trend is observed, but a plateau is found at lower EO molarity (i.e., higher salt concentration) indicating that the effect of interaction with lithium ions is stronger in the concentrated electrolyte. The peak position, also shown in Figure 6C, mirrors the absorbance trend. Bakker et al. (1995) and Bakker et al. (1996) claimed that stronger interaction between ether groups and cations causes a larger shift. In the present work, the shift was stronger at low salt concentration then became smaller at high salt concentration implying that the interaction between EO segments and lithium ion saturates at high salt concentration. This apparent contradiction as well as the mirroring of absorbance and peak position could be an artifact of deconvolution due to the strong overlap of the COC peak and LiTFSI peaks. This demonstrates that the COC absorbance is not appropriate for quantitative FTIR analysis.

The peaks between 1,100 and $800 \mathrm{~cm}^{-1}$ shown in Figure 6A originate from SEO, with the exception of $v_{\mathrm{a}} \mathrm{SNS}$ at $1,053 \mathrm{~cm}^{-1}$. The peak that is observed at $1,027 \mathrm{~cm}^{-1}$ in this study is more significantly contributed by the vibration of the phenyl groups of
PS (1,027 $\mathrm{cm}^{-1}$ ) (Liang and Krimm, 1958; van Asselen et al., 2004). The small plateau region between 1,046 and $1,037 \mathrm{~cm}^{-1}$ for the pure SEO (yellow solid line in Figure 6A) is thought to be contributed by a C-C-O-C-C deformation. The C-C-O-C-C conformational change around $1,045 \mathrm{~cm}^{-1}$ has been reported for pure PEO as having very weak intensity (Matsuura and Miyazawa, 1969; Yu and $\mathrm{Wu}$, 2007). Despite its weak intensity, the peak at $1,045 \mathrm{~cm}^{-1}$ along with the PS peak at $1,027 \mathrm{~cm}^{-1}$ makes the analysis of $v_{\mathrm{a}} \mathrm{SNS}$ difficult due to strong overlap. The $\mathrm{CH}_{2}$ rocking at $941 \mathrm{~cm}^{-1}\left(\rho \mathrm{CH}_{2}\right)$ showed an absorbance increase with increasing salt concentration while the other rocking bands showed decreases (990, 860-845, $\left.696 \mathrm{~cm}^{-1}\right)$. It is worth noting that the tail of the strong $v_{\mathrm{a}}$ SNS (Figure 6A) extends into this region and could impact the apparent absorbance changes of the PEO and PS bands, such as the $\mathrm{CH}_{2}$ increase.

The deconvoluted IR bands from Figure 6B between 805 and $713 \mathrm{~cm}^{-1}$ are shown in Figure 7A. The assignments of these peaks are not clear in many literature reports (Pennarun and Jannasch, 2005; Kam et al., 2014; Velez et al., 2016). These three peaks are thought to be shifted from 808,773 , and $745 \mathrm{~cm}^{-1}$ for the solid LiTFSI to 787,759 , and $739 \mathrm{~cm}^{-1}$ for the SEO/LiTFSI electrolyte at $r=0.17$. The assignments of these peaks are shown in Table 2. For pure LiTFSI, the IR peaks at 808 and $773 \mathrm{~cm}^{-1}$ seem to be complex combination peaks including the vibrations of $\mathrm{CS}, \mathrm{SN}$, and $\mathrm{CF}_{3}$ components (Rey et al., 1998a). However, there is agreement that the peak at $745 \mathrm{~cm}^{-1}$ in pure LiTFSI is the symmetric SNS vibration $\left(v_{s} \mathrm{SNS}\right)$. Upon incorporation of LiTFSI into SEO, all three of these peaks redshift. The peak at the highest frequency shifted from $808 \mathrm{~cm}^{-1}$ in pure LiTFSI to $787 \mathrm{~cm}^{-1}$ at $r=0.17 \mathrm{~mol}_{\mathrm{LiTFSI}} / \mathrm{mol}_{\mathrm{EO}}$; the middle peak shifted from 773 to $755 \mathrm{~cm}^{-1}$; and the lowest peak shifted from 745 to $740 \mathrm{~cm}^{-1}$. As a result, the peak at $787 \mathrm{~cm}^{-1}$ showed monotonic increase in absorbance without changing the peak position with increasing salt concentration with only minor overlap with the $\mathrm{CH}_{2}$ rocking band $\left(\rho \mathrm{CH}_{2}\right)$. The absorbance increase is presented quantitatively in Figure 7B. Like $v_{\mathrm{a}} \mathrm{CF}_{3}$ and $v_{\mathrm{a}} \mathrm{SO}_{2}$, the normalized, calibrated absorbance of the peak at $787 \mathrm{~cm}^{-1}$ (Figure $7 \mathbf{B}$ ) is more-or-less linear with salt concentration. The $787 \mathrm{~cm}^{-1}$ peak position also exhibits minor shifts mirroring those of $v_{\mathrm{a}} \mathrm{SO}_{2}$ that are too small for quantitative analysis. The other LiTFSI peaks seemingly split from $748 \mathrm{~cm}^{-1}$, but in fact, it is due to the growth of two different peaks $\left(v \mathrm{CS}, \nu_{s} \mathrm{~N}, \nu \mathrm{CF}_{3}\right.$ at $759 \mathrm{~cm}^{-1}$ and $v_{s}$ SNS at $740 \mathrm{~cm}^{-1}$ ) around the peak of benzene ring vibration $\left(748 \mathrm{~cm}^{-1}\right)$. Due to this overlap, no quantitative analysis was attempted.

Figure 8 presents the FTIR spectra of SEO, SEO/LiTFSI, and LiTFSI from 1,715 to $1,615 \mathrm{~cm}^{-1}$. No absorption was found in this region for the pure SEO nor for solid LiTFSI, but a peak clearly appears in the electrolyte at $1,675 \mathrm{~cm}^{-1}$. The peak location was constant for all samples. To the best of our knowledge, this peak has not been reported in literature for any PEO-based polymer electrolytes nor any LiTFSI-doped electrolytes. We propose that this peak is attributed to the ether-lithium interaction. An approximate argument for this assignment can be made using liquid water stretching as a reference $\left(\nu \cong 3,400 \mathrm{~cm}^{-1}\right)$. A simple rule of thumb that can be used to examine how vibrational 

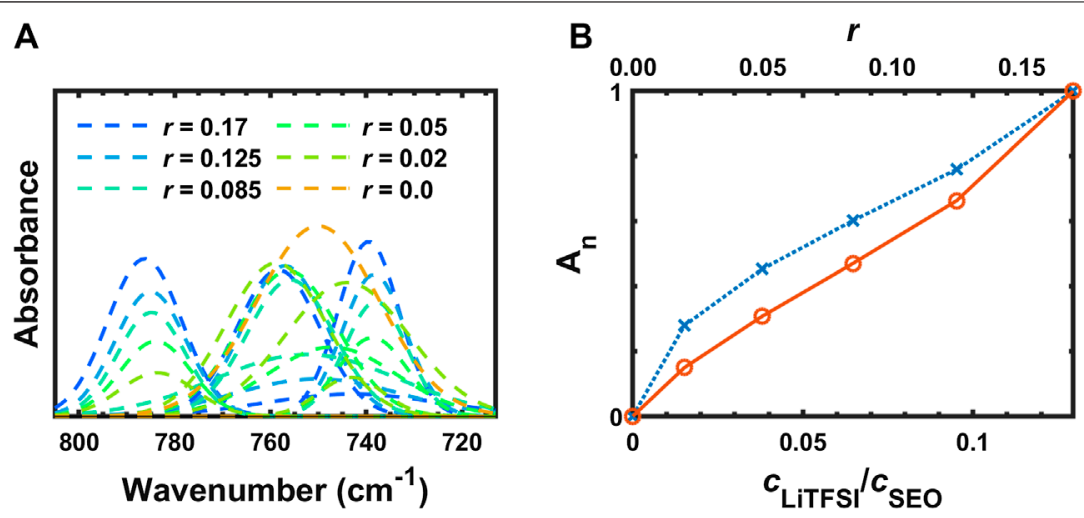

FIGURE 7| (A) Deconvoluted FTIR-ATR bands from 805 to $713 \mathrm{~cm}^{-1}$ and $\mathbf{( B )}$ concentration dependence of the peak integration of $\nu$ CS $\left(787 \mathrm{~cm}{ }^{-1}\right)\left(\cdots \times \cdots A_{n},-O-\right.$ $\left.A_{C, n}\right)$.

frequency will change upon change in mass of an atom in a functional group follows

$$
\nu=\frac{1}{2 \pi c} \sqrt{\frac{\kappa}{\mu}},
$$

where $c$ is speed of light, $\kappa$ is the force constant (related to the stiffness of the bond), and reduced mass is (Silverstein et al., 2005)

$$
\mu=\frac{m_{1} m_{2}}{m_{1}+m_{2}}
$$

As a zeroth order approximation assuming that $\kappa$ is constant, the shift on going from $\mathrm{H}_{2} \mathrm{O}$ stretching $\left(\mu_{\mathrm{H}_{2} \mathrm{O}}=1.79 \mathrm{~g} / \mathrm{mol}\right)$ to $\mathrm{Li}_{2} \mathrm{O}$ stretching $\left(\mu_{\mathrm{Li}_{2} \mathrm{O}}=7.43 \mathrm{~g} / \mathrm{mol}\right)$ is

$$
v_{\mathrm{Li}_{2} \mathrm{O}}=v_{\mathrm{H}_{2} \mathrm{O}} \sqrt{\frac{\mu_{\mathrm{H}_{2} \mathrm{O}}}{\mu_{\mathrm{Li}_{2} \mathrm{O}}}}=1,669 \mathrm{~cm}^{-1} .
$$

This is remarkable agreement with observation $\left(1,675 \mathrm{~cm}^{-1}\right)$, but clearly involves somewhat arbitrary assumptions. This peak assignment should be verified with simulations. A peak has been observed in liquid electrolyte at $1,650 \mathrm{~cm}^{-1}$ (Pyun, 1999). Along with several other peaks, it was assigned to a degradation product of $\mathrm{LiPF}_{6}$ and ethylene carbonate that contains $\mathrm{Li}-\mathrm{O}$ functionality and can be catalyzed by water presence. However, unlike the other peaks in that study, the absorbance at $1,650 \mathrm{~cm}^{-1}$ did not increase monotonically with water content. This could indicate that it actually corresponds to the coordinated $\mathrm{Li}-\mathrm{O}$ intermediate in the reaction scheme, which would support our peak assignment. It is worth mentioning that the water bending absorbance occurs in this region $\left(1,640 \mathrm{~cm}^{-1}\right)$. It is unlikely that the peak at $1,675 \mathrm{~cm}^{-1}$ is due to water contamination because our experimental setup has been design and tested to rigorously exclude exposure to air. Returning to experimental observations, the peak did not show any further absorbance increase on going from $r=0.125$ to $r=$ 0.17 . This might be due to the number of ether groups per lithium ion being saturated at $r=0.125$ (EO: $\left.\mathrm{Li}^{+}=8\right)$, resulting in incomplete dissociation of LiTFSI with addition of more salt. If additional Li cations are not generated with the addition of salt, then additional $\mathrm{Li}^{+}-\mathrm{O}$ coordination cannot form and the peak intensity will not increase. The normalized absorbance of this peak is shown in Figure 8B (blue dotted line with $\times$ marks), where it appears to plateau. However, if the effect of dilution is taken into
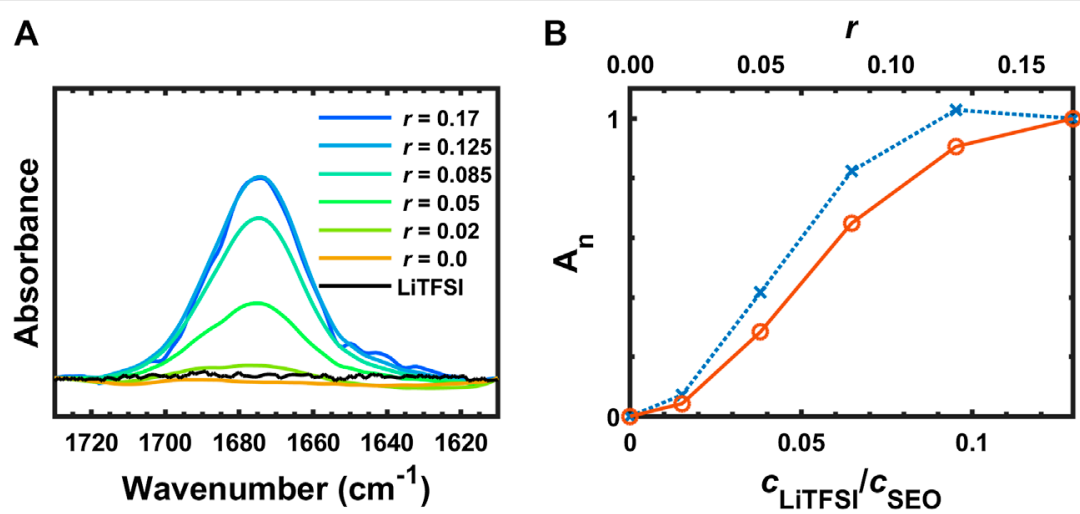

FIGURE 8 | (A) FTIR-ATR spectra of SEO, SEO/LiTFSI, and LiTFSI from 1,715 to $1,615 \mathrm{~cm}^{-1}$, and (B) normalized integration of (A) ( $\left.\cdots \times \cdots A_{n}\right)$ and normalized, calibrated absorbance $\left(-\mathrm{O}-A_{c, n}\right)$ 


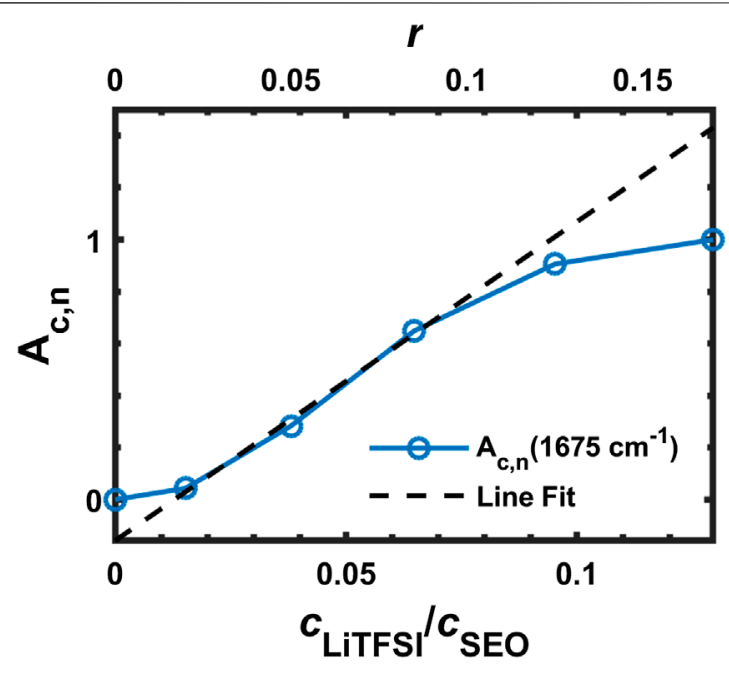

FIGURE $9 \mid A_{c, n}$ of the FTIR band at $1,675 \mathrm{~cm}^{-1}$ with line fitting

account using the normalized, calibrated absorbance (red solid line with $\bigcirc$ marks in Figure 8B), it can be seen that LiTFSI dissociation is not completely shut down at the highest salt concentration $\left(r=0.17, \mathrm{EO}: \mathrm{Li}^{+} \cong 6\right)$, but it is incomplete.

The data for $A_{c, n}\left(1,675 \mathrm{~cm}^{-1}\right)$ in Figure $8 \mathrm{~B}$ can be used to estimate the degree of dissociation. A line is fitted to the experimental data of $r=0.02-0.085$ that are assumed to be fully dissociated. The data at $r=0$ was excluded from the fitting due to the significantly different chemical environment indicated by the trend shown in Figure 2D. As shown in Figure 9, $A_{c, n}\left(1,675 \mathrm{~cm}^{-1}\right)$ falls below the line at $r=0.125$ and 0.17 . The degree of dissociation at the two highest salt concentrations was calculated by the deviation of the experimental data from the line. The SEO/LiTFSI electrolyte is found to be $90 \%$ dissociated at $r=$ 0.125 and $70 \%$ dissociated at $r=0.17$. This finding is in relatively good agreement with a study by Edman, who used a Raman mode associated with $\mathrm{Li}^{+}$-PEO coordination to conclude that dissociation in PEO-LiTFSI electrolyte above $\mathrm{EO}: \mathrm{Li}^{+} \cong 8$ is incomplete (Edman, 2000). In particular, Edman found that LiTFSI nearly completely dissociates in PEO at $r=0.125$, but that LiTFSI is only 76\% dissociated at $r=0.17$. Agreement was also found from a recent study of PEO-based polymer electrolyte and NaTf system (Lehmann et al., 2019). A strong decrease of ionic conductivity was observed above EO: $\mathrm{Na}^{+}=12(20 \mathrm{wt} \%)$ for dry linear PEO-NaTf. The FTIR spectra of PEO-NaTf showed that aggregates appeared for the salt concentrations above EO: $\mathrm{Na}^{+}=8: 1$. The agreement among the three studies using two different techniques strengthens the conclusions and indicates that the presence of PS in the block copolymer does not have a significant impact on dissociation state of the salt in the PEO phase.

Several computations were conducted following the approach of Han et al. (2017), in which DFT calculation has been used to support experimental results of FTIR and Raman spectroscopy. In this study, computations were conducted in order to identify a potential origin for the peak that appears at
$1,675 \mathrm{~cm}^{-1}$ as the LiTFSI is added to the system. We have initially tested if the peak originates from the coordination of the Li cation and the PEO backbone. In order to look at Li-PEO coordination, a fragment of the PEO backbone was modeled as coordinated with a Li-cation. Backbone fragments consisting of a single chain containing either two or three oxygens (1,2dimethoxyethane and 1-methoxy-2-(2-methoxyethoxy)ethane respectively), and two individual chains of 1,2-dimethoxyethane were explored as potential Li-PEO interaction sites that could be occurring experimentally. Vibrations corresponding to the $\mathrm{C}-\mathrm{H}$ bonds before and after Li-coordination were in agreement with the experimentally determined spectra suggesting that our model system is a good approximation to the experimental system. The experimental peak at approximately $1,500 \mathrm{~cm}^{-1}$ corresponds to $\mathrm{C}-\mathrm{H}$ stretching on the PEO-backbone and therefore was used as a reference peak for the calculated IR spectra. All three potential Li-PEO coordination calculations had the expected peak around $1,500 \mathrm{~cm}^{-1}$ but did not have a peak around the region of interest [both before and after scaling (by 0.964)], suggesting that the peak at $1,675 \mathrm{~cm}^{-1}$ is not from Li-PEO coordination. Next, the potential for the TFSI counterion interacting with the Li-PEO system was explored. These simulated IR spectra also had the internal standard peak at $\sim 1,500 \mathrm{~cm}^{-1}$ corresponding to $\mathrm{C}-\mathrm{H}$ stretching of the $\mathrm{PEO}$ backbone. The other PEO backbone peaks overlap with the peaks experimentally shown to correspond to the LiTFSI salt making it difficult to differentiate most of the other IR signals. Despite this, the expanded system also did not result in a peak around $1,675 \mathrm{~cm}^{-1}$.

The potential presence of water was explored next where the $\mathrm{Li}-\mathrm{PEO}$ system formed a $\mathrm{Li}^{+} \ldots \mathrm{OH}_{2}$ complex with a water molecule. Based off the computations of the Li-PEO systems with and without water, there are expected to be additionally three peaks resulting from water. The first peak will appear around $1,660-1,600 \mathrm{~cm}^{-1}$ and the other two peaks are expected to occur around $\sim 3,750$ and $\sim 3,650 \mathrm{~cm}^{-1}$ (Figure 10A). When calculated all three peaks had similar intensities meaning if the first peak at $1,675 \mathrm{~cm}^{-1}$ truly corresponds to water then the other peaks should be observable unless PS is IR-active in these regions. This system displayed a peak at $1,660 \mathrm{~cm}^{-1}$ before scaling $\left(\sim 1,600 \mathrm{~cm}^{-1}\right.$ after scaling by 0.964 ) that corresponded to $\mathrm{O}-\mathrm{H}$ wagging from the water molecule. This result indicates that the presence of water might cause the IR band around $1,675 \mathrm{~cm}^{-1}$ in the experimental system. However, there is no indication of $\mathrm{OH}$ stretching $\left(3,130-3,740 \mathrm{~cm}^{-1}\right)$ absorbance in the experimental spectra (Figure 10B), and the $\mathrm{OH}$ stretching vibration is a stronger absorber than the $\mathrm{HOH}$ bending vibration (Figure 10B).

Other potential interactions between $\mathrm{Li}$ and oxygen-based impurities were explored in order to rule out their involvement. A hydroxy-anion coordinated to the Li cation in the Li-PEO system did not produce a peak around the $1,675 \mathrm{~cm}^{-1}$ region. Finally, the IR spectra for an oxygen-bridge between the two Li-PEO systems was explored too. Again, formation of a $\mathrm{Li}-\mathrm{O}-\mathrm{Li}$ bridge did not result in a peak around the region of interest.

Interestingly, stereoelectronic effects were found in the calculated IR spectra for the $\mathrm{C}-\mathrm{H}$ bond vibration region 

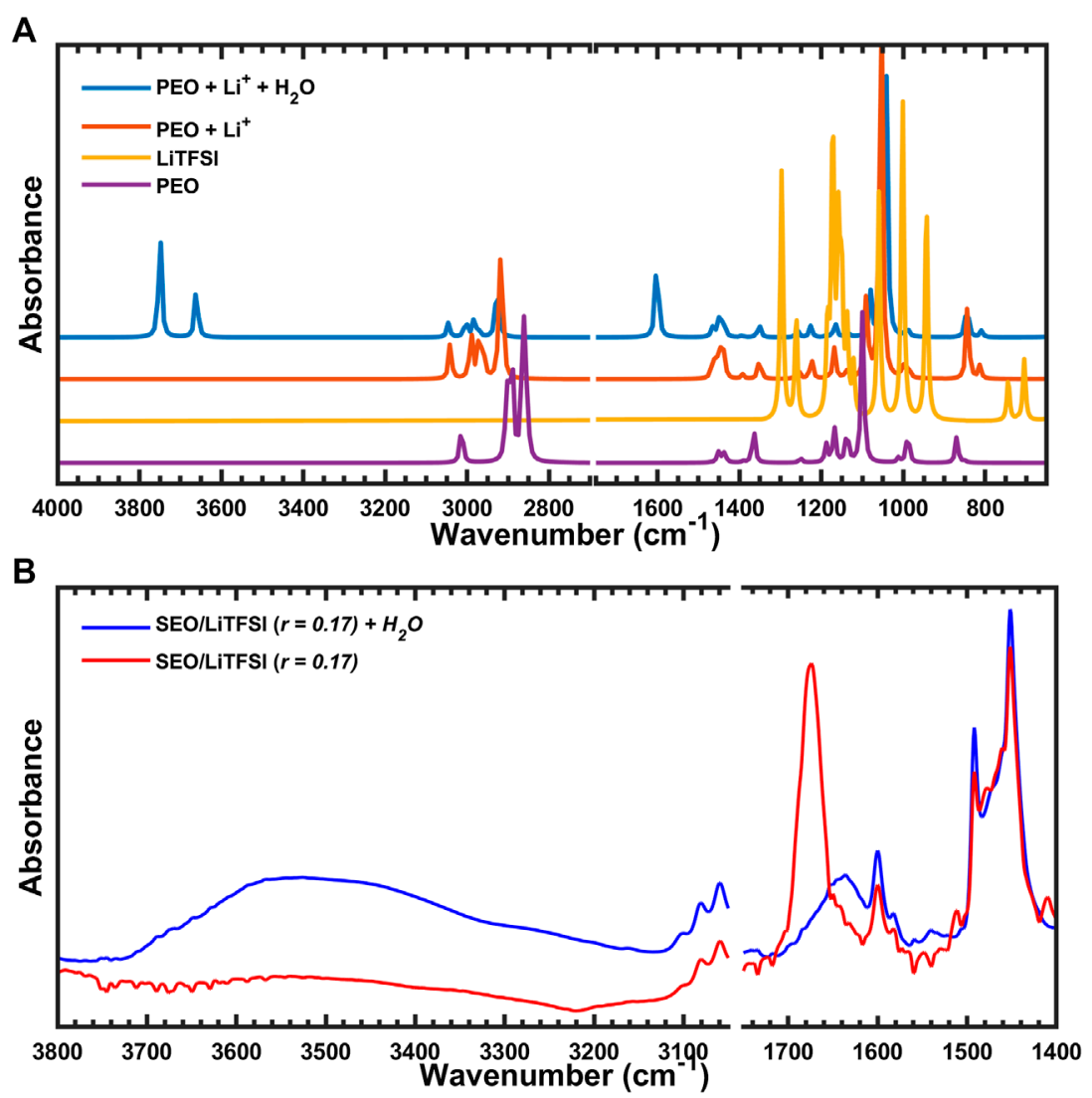

FIGURE 10 | (A) Simulated IR spectra of PEO coordinated with $\mathrm{Li}^{+}$and $\mathrm{H}_{2} \mathrm{O}$, and (B) experimental FTIR-ATR spectra of SEO/LiTFSI with or without water.

$\left(\sim 3,000 \mathrm{~cm}^{-1}\right)$ when converting from the uncoordinated trans conformer to the Li-coordinated gauche configuration. These changes originate from the attenuation of anomeric effect (Juaristi and Cuevas, 1992; Alabugin, 2000; Kirby, 2012; Gomes et al., 2015) When uncoordinated, the lone pairs of oxygen are able to donate electron density to the antibonding $\mathrm{C}-\mathrm{H}$ orbitals, effectively weakening the $\mathrm{C}-\mathrm{H}$ bonds. However, in order for the PEO backbone to coordinate with the lithium cation it must adopt a gauche conformation and the oxygen uses one of its lone pairs to coordinate with lithium. As a consequence, oxygen has only one lone pair that can participate in hyperconjugation with the $\mathrm{C}-\mathrm{H}$ bond and the orbital overlap between the donor and acceptor has been compromised due to the now gauche geometry. Both of these factors decrease the average donor ability of oxygen from $6 \mathrm{kcal} / \mathrm{mol}$ in the uncoordinated configuration to $4.2 \mathrm{kcal} / \mathrm{mol}$ in the Li-coordinated complex according to NBO analysis (Glendening et al., 2012). Due to the weaker donor ability of oxygen in the gauche conformer the IR peaks corresponding to $\mathrm{C}-\mathrm{H}$ bond vibrations are blue-shifted in comparison to the trans-conformer spectra, as shown in Figure 11A. Although somewhat less pronounced, the same blue shift is seen in the experimental spectra of Figure 11B, where the $\mathrm{C}-\mathrm{H}$ bond vibration in question monotonically shifts from $2,860 \mathrm{~cm}^{-1}$ in the neat polymer to $2,882 \mathrm{~cm}^{-1}$ at $r=0.17 \mathrm{~mol}_{\mathrm{Li}} / \mathrm{mol}_{\mathrm{EO}}$ (Table 2). In other words, the simulated and experimental spectra both indicate that the amount of gauche PEO conformations increase with addition of LiTFSI salt to the polymer, and the computational modeling provides molecular insight into the origin of these changes.

The interaction of cation and NMP was also studied experimentally since the $\mathrm{C}=\mathrm{O}$ double bond has a peak around $1,675 \mathrm{~cm}^{-1}$. The spectrum of a solution of NMP and LiTFSI, shown in Figure $\mathbf{1 2 A}$, exhibits a large $\mathrm{C}=\mathrm{O}$ peak. After collecting the spectrum of the solution, the LiTFSI/NMP mixture on the ATR crystal was brought into the argon-filled glovebox, unsealed, and dried overnight at $60^{\circ} \mathrm{C}$. The sample was further dried for one more overnight under vacuum at $60^{\circ} \mathrm{C}$. Then another FTIR spectrum was collected of the LiTFSI dried from solution. This spectrum is shown in Figure 12A along with a spectrum of as-received LiTFSI that had never been exposed to NMP. There are distinct differences between the LiTFSI salt dried from solution and the as-received LiTFSI. For the most part, the LiTFSI peaks in the wavenumber range from 1,550 to $650 \mathrm{~cm}^{-1}$ agree between the dried and the as-received salt. On the other hand, a weak peak remains at $1,675 \mathrm{~cm}^{-1}$ (and $3,050-2,800 \mathrm{~cm}^{-1}$, not shown) in the LiTFSI salt dried from solution, whereas there are no indications of these peaks in the 

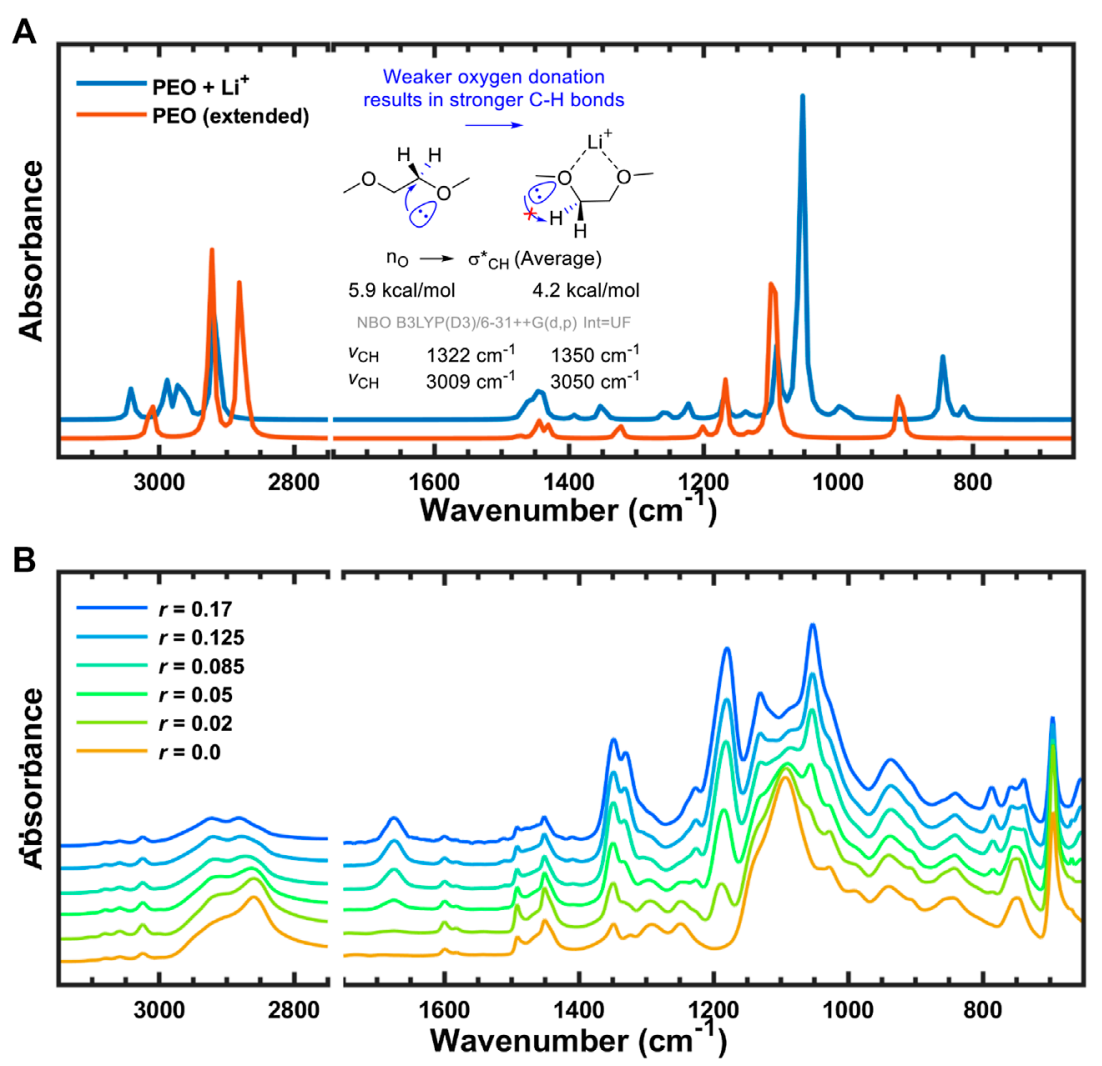

FIGURE 11 | FTIR-ATR spectra with anomeric effect from (A) simulation with scaling factor of 0.964, and (B) experiment.

as-received salt. This seems to indicate that there is strong solvation between LiTFSI and NMP, and that NMP-LiTFSI complex remains in polymer electrolytes processed with this solvent. It is known that large dielectric constant of PEO reduces ion-ion interaction and leads to higher ion mobility (Wheatle et al., 2017). However, when there is solvent with larger dielectric constant than polymer, lithium cation is likely coordinated to solvent rather than polymer (Ford et al., 2020). We propose that the formation of Li-NMP complex depends on the amount of lithium salt. To prove this, salt diffusion test was set up as described in our previous study (Kim and Hallinan, 2020) with the membrane of higher salt concentration placed below the membrane with lower salt concentration. Figure 12B represents the time-resolved FTIR spectra where the LiTFSI diffuses from the bottom to the top membrane. The initial spectrum is represented as orange line and the final spectrum is blue. The peak at $1,675 \mathrm{~cm}^{-1}$ decreased with decreasing LiTFSI concentration supporting the assertion that this peak is from a complex containing LiTFSI.
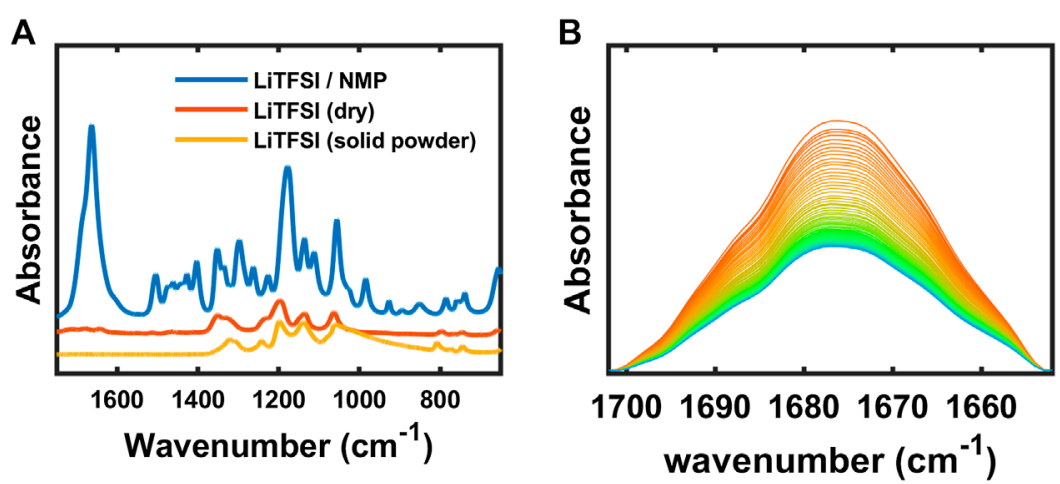

Figure 12 | (A) FTIR-ATR spectra of LiTFSI + NMP, dry LiTFSI and solid LiTFSI powder, and (B) time-resolved FTIR-ATR spectra of SEO/LiTFSI with diffusion. 


\section{CONCLUSION}

In this study, the dissociation of LiTFSI in the amorphous PEO conducting phase of an SEO diblock copolymer electrolyte was investigated using FTIR-ATR spectroscopy. Quantitative analysis showed increasing interactions between the salt molecule and ethylene oxide chains with increasing salt concentration and a lack of complete dissociation at the highest salt concentration studied. The inert polystyrene block worked as a reliable indicator of the consistency of the Beer-Lambert law at high salt concentration. In other words, the absorbance of polystyrene peaks decreased with increasing LiTFSI content (due to dilution), but lacked any detectable interaction with the salt. The PEO phase, however, was found to interact strongly with $\mathrm{Li}^{+}$. Conformational changes of the PEO backbone upon $\mathrm{Li}^{+}$ complexation were detected via relative changes of $\mathrm{CH}_{2}$ vibrations $\left({ }_{\tau} \mathrm{CH}_{2}\right)$ and a blue shift of $\mathrm{CH}$ stretching due to the anomeric effect that was identified via simulations. Note that TFSI peaks, for the most part, exhibited only weak changes connected to anion conformations with changing salt concentration. On the other hand, large spectral changes indicative of conformational changes of the ether backbone of PEO were evident with changing salt concentration. The appearance of a previously unidentified peak at $1,675 \mathrm{~cm}^{-1}$ was attributed to NMP-LiTFSI complexation, indicating that polymer electrolytes processed with NMP contain residual solvent strongly solvating the LiTFSI salt. Analysis of this peak at $1,675 \mathrm{~cm}^{-1}$, led to the same conclusions as those reached in a separate Raman study of PEO-LiTFSI electrolyte, namely that incomplete salt dissociation begins above $r=0.125\left(\mathrm{EO}: \mathrm{Li}^{+}=8\right)$. Dissociation and chemical environment of the lithium salt was therefore surprisingly determined primarily from FTIR-ATR spectral changes associated with the polymer rather than those of the TFSI anions. The agreement between FTIR and Raman spectroscopy strengthens the claims of both studies. The comparison of composite SEO electrolyte with PEO electrolyte

\section{REFERENCES}

Alabugin, I. V. (2000). Stereoelectronic interactions in cyclohexane, 1,3-dioxane, 1,3-oxathiane, and 1,3-dithiane: W-effect, $\sigma \mathrm{C}-\mathrm{X} \leftrightarrow \sigma^{\star} \mathrm{C}-\mathrm{H}$ interactions, anomeric effect what is really important? J. Org. Chem. 65 (13), 3910-3919. doi:10.1021/jo991622+.

Aravindan, V., Gnanaraj, J., Madhavi, S., and Liu, H.-K. (2011). Lithium-ion conducting electrolyte salts for lithium batteries. Chem. Eur. J. 17 (51), 14326-14346. doi:10.1002/chem.201101486.

Arnaud, R., Benrabah, D., and Sanchez, J.-Y. (1996). Theoretical Study of CF3SO3Li, (CF3SO2)2NLi, and (CF3SO2)2CHLi Ion Pairs. J. Phys. Chem. 100 (26), 10882-10891. doi:10.1021/jp953259q.

Bakker, A., Gejji, S., Lindgren, J., Hermansson, K., and Probst, M. M. (1995). Contact ion pair formation and ether oxygen coordination in the polymer electrolytes $\mathrm{M}[\mathrm{N}(\mathrm{CF} 3 \mathrm{SO} 2) 2] 2 \mathrm{PEOn}$ for $\mathrm{M}=\mathrm{Mg}, \mathrm{Ca}, \mathrm{Sr}$ and $\mathrm{Ba}$. Polymer 36 (23), 4371-4378. doi:10.1016/0032-3861(95)96841-u.

Bakker, A., Lindgren, J., and Hermansson, K. (1996). Polymer electrolytes based on triblock-copoly(oxyethylene/oxypropylene/oxyethylene) systems. Polymer 37 (10), 1871-1878. doi:10.1016/0032-3861(96)87303-4.

Begum, R., and Matsuura, H. (1997). Conformational properties of short poly(oxyethylene) chains in water studied by IR spectroscopy. Faraday Trans. 93 (21), 3839-3848. doi:10.1039/a703436i. further indicates that PS does not significantly affect salt dissociation nor ion-PEO interaction. The findings from this work gives many interesting aspects to be explored and will work as a useful resource in study of polymer electrolyte systems.

\section{DATA AVAILABILITY STATEMENT}

All datasets presented in this study are included in the article/ Supplementary Material.

\section{AUTHOR CONTRIBUTIONS}

The manuscript was written through contributions of all authors. KK conducted the FTIR experiment and analysis. LK conducted the DFT calculations. All authors have given approval to the final version of the manuscript.

\section{FUNDING}

This work was supported by the National Science Foundation award number 1804871.

\section{ACKNOWLEDGMENTS}

The authors would like to acknowledge assistance from the FAMU-FSU. College of Engineering Machine Shop.

\section{SUPPLEMENTARY MATERIAL}

The Supplementary Material for this article can be found online at: https://www.frontiersin.org/articles/10.3389/fenrg.2020.569442/ full\#supplementary-material

Berliner, M. D., McGill, B. C., Majeed, M., and Hallinan, D. T. (2019). Electrochemical kinetics of lithium plating and stripping in solid polymer electrolytes: pulsed voltammetry. J. Electrochem. Soc. 166 (2), A297-A304. doi:10.1149/2.0851902jes.

Borodin, O., and Smith, G. D. (2006). Mechanism of ion transport in amorphous poly(ethylene oxide)/LiTFSI from molecular dynamics simulations. Macromolecules 39 (4), 1620-1629. doi:10.1021/ma052277v.

Chintapalli, M., Le, T. N. P., Venkatesan, N. R., Mackay, N. G., Rojas, A. A., Thelen, J. L., et al. (2016). Structure and ionic conductivity of polystyrene-blockpoly(ethylene oxide) electrolytes in the high salt concentration limit. Macromolecules 49 (5), 1770-1780. doi:10.1021/acs.macromol.5b02620.

Chiu, C.-Y., Yen, Y.-J., Kuo, S.-W., Chen, H.-W., and Chang, F.-C. (2007). Complicated phase behavior and ionic conductivities of PVP-co-PMMAbased polymer electrolytes. Polymer 48 (5), 1329-1342. doi:10.1016/j. polymer.2006.12.059.

Devaux, D., Glé, D., Phan, T. N. T., Gigmes, D., Giroud, E., Deschamps, M., et al. (2015). Optimization of block copolymer electrolytes for lithium metal batteries. Chem. Mater. 27 (13), 4682-4692. doi:10.1021/acs.chemmater. $5 \mathrm{~b} 01273$.

Denoyel, M. A. K. L., and Frech, R. (1995). Infrared spectroscopic study of the phases and phase transitions in poly(ethylene oxide) and poly(ethylene oxide)lithium trifluoromethanesulfonate complexes. Macromolecules 28 (15), 5312-5319. doi:10.1021/ma00119a022. 
Edman, L. (2000). Ion association and ion solvation effects at the crystalline-amorphous phase transition in PEO-LiTFSI. J. Phys. Chem. B 104 (31), 7254-7258. doi:10.1021/jp000082d.

Elabd, Y. A., Baschetti, M. G., and Barbari, T. A. (2003). Time-resolved Fourier transform infrared/attenuated total reflection spectroscopy for the measurement of molecular diffusion in polymers. J. Polym. Sci. B Polym. Phys. 41 (22), 2794-2807. doi:10.1002/polb.10661.

Ferry, A., Jacobsson, P., and Torell, L. M. (1995). The molar conductivity behavior in polymer electrolytes at low salt concentrations; A Raman study of poly(propylene glycol) complexed with LiCF3SO3. Electrochimica Acta 40 (13), 2369-2373. doi:10.1016/0013-4686(95)00196-1

Fieldson, G. T., and Barbari, T. A. (1993). The use of FTi.r.-a.t.r. spectroscopy to characterize penetrant diffusion in polymers. Polymer 34 (6), 1146-1153. doi:10.1016/0032-3861(93)90765-3.

Ford, H. O., Park, B., Jiang, J. Z., Seidler, M. E., and Schaefer, J. L. (2020). Enhanced $\mathrm{Li}+$ conduction within single-ion conducting polymer gel electrolytes via reduced cation-polymer interaction. ACS Mater. Lett. 2 (3), 272-279. doi:10. 1021/acsmaterialslett.9b00510.

Frisch, M. J. T., Schlegel, H. B., Scuseria, G. E., Robb, M. A., Cheeseman, J. R., Scalmani, G., et al. (2009). "Gaussian 09." 01E. ed.

GaussView, P. (2009). 5.0. 9. Dennington R., Keith TA, Millam JM, Semichem Inc., Shawnee Mission, KS.

Glendening, E. D., Landis, C. R., and Weinhold, F. (2012). Natural bond orbital methods. WIREs Comput. Mol. Sci. 2 (1), 1-42. doi:10.1002/wcms.51.

Glendening, E., Reed, A., Carpenter, J., and Weinhold, F. (1998). "NBO Version 3.1".).

Gomes, G. d. P., Vil', V. A., Terent'ev, A. O., and Alabugin, I. V. (2015). Stereoelectronic source of the anomalous stability of bis-peroxides. Chem. Sci. 6 (12), 6783-6791. doi:10.1039/c5sc02402a.

Goodenough, J., Abruna, H., and Buchanan, M. (2007). "Basic research needs for electrical energy storage. Report of the basic energy sciences workshop on electrical energy storage, April 2-4, 2007.” DOESC (United States: USDOE Office of Science (SC)).

Hallinan, D. T., and Balsara, N. P. (2013). "Polymer electrolytes," in Annual Review of materials research, Vol. 43, ed. D. R. Clarke. (Palo Alto: Annual Reviews, 503.

Hallinan, D. T., and Elabd, Y. A. (2007). Diffusion and sorption of methanol and water in nafion using time-resolved Fourier transform infrared-attenuated total reflectance spectroscopy. J. Phys. Chem. B 111 (46), 13221-13230. doi:10. 1021/jp075178n.

Hallinan, D. T., Mullin, S. A., Stone, G. M., and Balsara, N. P. (2013). Lithium metal stability in batteries with block copolymer electrolytes. J. Electrochem. Soc. 160 (3), A464-A470. doi:10.1149/2.030303jes.

Hallinan, D. T., Villaluenga, I., and Balsara, N. P. (2018). Polymer and composite electrolytes. MRS Bull. 43 (10), 759-767. doi:10.1557/mrs.2018.212.

Han, L., Iguchi, D., Gil, P., Heyl, T. R., Sedwick, V. M., Arza, C. R., et al. (2017). Oxazine ring-related vibrational modes of benzoxazine monomers using fully aromatically substituted, deuterated, $15 \mathrm{~N}$ isotope exchanged, and oxazine-ringsubstituted compounds and theoretical calculations. J. Phys. Chem. A 121 (33), 6269-6282. doi:10.1021/acs.jpca.7b05249.

Ohashi, M., Smirnov, M., Johansson, P., Chami, M., Grondin, J., Servant, L., et al. (2005). Spectroscopic characterization of the conformational states of the bis(trifluoromethanesulfonyl)imide anion (TFSI-). J. Raman Spectrosc. 36 (8), 762-770. doi:10.1002/jrs.1347.

Lassègues, E., and Peppas, N. A. (1993). Use of ATR-FTIR to study interdiffusion in polystyrene and poly(vinyl methyl ether). Macromolecules 26 (9), 2175-2186. doi:10.1021/ma00061a006.

Jo, G., Ahn, H., and Park, M. J. (2013). Simple route for tuning the morphology and conductivity of polymer electrolytes: one end functional group is enough. ACS Macro Lett. 2 (11), 990-995. doi:10.1021/mz400468m.

Johnson III, R. (2019). NIST computational chemistry comparison and benchmark database, NIST standard reference Database number 101, Release 20, 2019.

Juaristi, E., and Cuevas, G. (1992). Recent studies of the anomeric effect. Tetrahedron 48 (24), 5019-5087. doi:10.1016/s0040-4020(01)90118-8.

Judez, X., Zhang, H., Li, C. M., Eshetu, G. G., González-Marcos, J. A., Armand, M., et al. (2018). Review-solid electrolytes for safe and high energy density lithiumsulfur batteries: promises and challenges. J. Electrochem. Soc. 165 (1), A6008-A6016. doi:10.1149/2.0041801jes.

Rodriguez-Martinez, M., Schantz, S., and Torell, L. M. (1990). Raman spectroscopic study of ion-ion interaction and its temperature dependence in a poly(propylene-oxide)-based $\mathrm{NaCF}_{3} \mathrm{SO}_{3}$-polymer electrolyte. J. Chem. Phys. 92 (10), 6271-6277. doi:10.1063/1.458351.

Kam, W., Liew, C.-W., Lim, J. Y., and Ramesh, S. (2014). Electrical, structural, and thermal studies of antimony trioxide-doped poly(acrylic acid)-based composite polymer electrolytes. Ionics 20 (5), 665-674. doi:10.1007/s11581013-1012-0.

Kim, K., and Hallinan, D. T. (2020). Lithium salt diffusion in diblock copolymer electrolyte using Fourier transform infrared spectroscopy. J. Phys. Chem. B 124 (10), 2040-2047. doi:10.1021/acs.jpcb.9b11446.

Kirby, A. J. (2012). The anomeric effect and related stereoelectronic effects at oxygen. Berlin: Springer Science \& Business Media.

Lappi, S. E., Smith, B., and Franzen, S. (2004). Infrared spectra of , and D2O in the liquid phase by single-pass attenuated total internal reflection spectroscopy. Spectrochim. Acta Part A Mol. Biomol. Spectrosc. 60 (11), 2611-2619. doi:10. 1016/j.saa.2003.12.042.

Legault, C. (2009). "CYLview, version 1.0 b; Universitede Sherbrooke: Quebec, Canada).

Lehmann, M. L., Yang, G., Gilmer, D., Han, K. S., Self, E. C., Ruther, R. E., et al. (2019). Tailored crosslinking of poly(ethylene oxide) enables mechanical robustness and improved sodium-ion conductivity. Energy Storage Mater. 21, 85-96. doi:10.1016/j.ensm.2019.06.028.

Ge, M., Lu, J., Chen, Z. W., and Amine, K. (2018). 30 years of lithium-ion batteries. Adv. Mater. 30 (33), 1800561. doi:10.1002/adma.201800561.

Liang, C. Y., and Krimm, S. (1958). Infrared spectra of high polymers. VI. Polystyrene. J. Polym. Sci. 27 (115), 241-254. doi:10.1002/pol.1958.1202711520.

Lu, M. F., Runt, J., and Painter, P. (2009). An infrared spectrocopic study of a polyester copolymer ionomer based on poly(ethylene oxide). Macromolecules 42 (17), 6581-6587. doi:10.1021/ma900978d.

Majeed, M. (2019). Ionic conductivity and reaction kinetics of lithium electrodes with solid polymer electrolytes. BS Undergraduate Honors, Tallahassee: Florida State University.

Matsuo, M., Ueno, T., Horino, H., Chujyo, S., and Asai, H. (1968). Fine structures and physical properties of styrene-butadiene block copolymers. Polymer 9 (8), 425-429. doi:10.1016/0032-3861(68)90052-9.

Matsuura, H., and Fukuhara, K. (1986). Vibrational spectroscopic studies of conformation of poly(oxyethylene). II. conformation-spectrum correlations. J. Polym. Sci. B Polym. Phys. 24 (7), 1383-1400. doi:10.1002/polb.1986. 090240702.

Matsuura, H., and Miyazawa, T. (1969). Vibrational analysis of molten poly(ethylene glycol). J. Polym. Sci. A-2 Polym. Phys. 7 (10PA), 1735-\&. doi:10.1002/pol.1969.160071009.

Metwalli, E., Rasool, M., Brunner, S., and Müller-Buschbaum, P. (2015). Lithiumsalt-containing high-molecular-weight polystyrene-block-polyethylene oxide block copolymer films. ChemPhysChem 16 (13), 2882-2889. doi:10.1002/ cphc. 201500358.

Niitani, T., Shimada, M., Kawamura, K., and Kanamura, K. (2005). Characteristics of new-type solid polymer electrolyte controlling nano-structure. J. Power Sources 146 (1-2), 386-390. doi:10.1016/j.jpowsour.2005.03.102.

Oparaji, O. D. (2017). Influence of molecular transport on the structure-property relationships of amphiphilic block copolymer membranes. Ph.D, Tallahassee: Florida State University.

Oparaji, O., Narayanan, S., Sandy, A., Ramakrishnan, S., and Hallinan, D. (2018). Structural dynamics of strongly segregated block copolymer electrolytes. Macromolecules 51 (7), 2591-2603. doi:10.1021/acs.macromol.7b01803.

Oparaji, O., Zuo, X. B., and Hallinan, D. T. (2016). Crystallite dissolution in PEObased polymers induced by water sorption. Polymer 100, 206-218. doi:10.1016/ j.polymer.2016.08.026.

Panday, A., Mullin, S., Gomez, E. D., Wanakule, N., Chen, V. L., Hexemer, A., et al. (2009). Effect of molecular weight and salt concentration on conductivity of block copolymer electrolytes. Macromolecules 42 (13), 4632-4637. doi:10.1021/ ma900451e.

Pennarun, P. Y., and Jannasch, P. (2005). Influence of the alkali metal salt on the properties of solid electrolytes derived from a Lewis acidic polyether. Solid State Ionics 176 (23-24), 1849-1859. doi:10.1016/j.ssi.2005.05.014.

Pesko, D. M., Timachova, K., Bhattacharya, R., Smith, M. C., Villaluenga, I., Newman, J., et al. (2017). Negative transference numbers in poly(ethylene oxide)-based electrolytes. J. Electrochem. Soc. 164 (11), E3569-E3575. doi:10. 1149/2.0581711jes. 
Pesko, D. M., Webb, M. A., Jung, Y. Y., Zheng, Q., Miller, T. F., Coates, G. W., et al. (2016). Universal relationship between conductivity and solvation-site connectivity in ether-based polymer electrolytes. Macromolecules 49 (14), 5244-5255. doi:10.1021/acs.macromol.6b00851.

Balsara, L., Sammon, C., Lyon, S. B., and Yarwood, J. (2004). An FTIR/ATR in situ study of sorption and transport in corrosion protective organic coatings. Prog. Org. Coat. 49 (4), 315-323. doi:10.1016/j.porgcoat.2003.10.007.

Pyun, S.-I. (1999). In-situ spectroelectrochemical analysis of the passivating surface film formed on a carbon film electrode as a function of the water content in $1 \mathrm{M}$ LiPF 6 -EC/DEC solution. Fresenius'J. Anal. Chem. 363 (1), 38-45. doi:10.1007/ s002160051135.

Rey, I., Johansson, P., Lindgren, J., Lassègues, J. C., Grondin, J., and Servant, L. (1998a). Spectroscopic and theoretical study of (CF3SO2)2N-(TFSI-) and (CF3SO2)2NH (HTFSI). J. Phys. Chem. A 102 (19), 3249-3258. doi:10.1021/ jp980375v.

Rey, I., Lassègues, J. C., Grondin, J., and Servant, L. (1998b). Infrared and Raman study of the PEO-LiTFSI polymer electrolyte. Electrochim. Acta 43 (10-11), 1505-1510. doi:10.1016/s0013-4686(97)10092-5.

Rosedale, J. H., and Bates, F. S. (1990). Rheology of ordered and disordered symmetric poly(ethylenepropylene)-poly(ethylethylene) diblock copolymers. Macromolecules 23 (8), 2329-2338. doi:10.1021/ma00210a032.

Ruck, S., Enderle, S., Bolsinger, M., Weller, M., Knoblauch, V., and Riegel, H. (2019). "Enhancing the rate capability of highly densified Li-ion battery cathodes by selective laser ablation," in Laser-based micro- and nanoprocessing XIII, eds. U. Klotzbach, A. Watanabe, and R. Kling. (Bellingham: Spie-Int Soc Optical Engineering).

Ruzette, A.-V. G., Soo, P. P., Sadoway, D. R., and Mayes, A. M. (2001). Meltformable block copolymer electrolytes for lithium rechargeable batteries. J. Electrochem. Soc. 148 (6), A537-A543. doi:10.1149/1.1368097.

Sammon, C., Mura, C., Yarwood, J., Everall, N., Swart, R., and Hodge, D. (1998). FTIR-ATR studies of the structure and dynamics of water molecules in polymeric matrixes. a comparison of PET and PVC. J. Phys. Chem. B 102 (18), 3402-3411. doi:10.1021/jp980169n.

Seo, Y., Shen, K.-H., Brown, J. R., and Hall, L. M. (2019). Role of solvation on diffusion of ions in diblock copolymers: understanding the molecular weight effect through modeling. J. Am. Chem. Soc. 141 (46), 18455-18466. doi:10.1021/ jacs.9b07227.

Shieh, Y.-T., and Liu, K.-H. (2004). Conformational changes of poly(ethylene oxide) in poly(ethylene oxide)/poly(methyl methacrylate) blends by supercritical carbon dioxide. J. Polym. Sci. B Polym. Phys. 42 (13), 2479-2489. doi:10.1002/polb.10492.

Silverstein, R. M., Kiemle, D. J., and Webster, F. X. (2005). Spectrometric identification of organic compounds. Hoboken, NJ: John Wiley \& Sons.

Stone, G. M., Mullin, S. A., Teran, A. A., Hallinan, D. T., Minor, A. M., Hexemer, A., et al. (2012). Resolution of the modulus versus adhesion dilemma in solid polymer electrolytes for rechargeable lithium metal batteries. J. Electrochem. Soc. 159 (3), A222-A227. doi:10.1149/2.030203jes.

Suo, L. M., Zheng, F., Hu, Y.-S., and Chen, L. Q. (2016). FT-Raman spectroscopy study of solvent-in-salt electrolytes. Chinese Phys. B 25 (1), 016101. doi:10.1088/ 1674-1056/25/1/016101.
Teran, A. A., and Balsara, N. P. (2014). Thermodynamics of block copolymers with and without salt. J. Phys. Chem. B 118 (1), 4-17. doi:10.1021/ jp408079z.

van Asselen, O. L. J., van Casteren, I. A., Goossens, J. G. P., and Meijer, H. E. H. (2004). Deformation behavior of triblock copolymers based on polystyrene: an FT-IR spectroscopy study. Macromol. Symp. 205, 85-94. doi:10.1002/masy. 200450108.

Vélez, J. F., Aparicio, M., and Mosa, J. (2016). Effect of lithium salt in nanostructured silica-polyethylene glycol solid electrolytes for Li-Ion battery applications. J. Phys. Chem. C 120 (40), 22852-22864. doi:10.1021/acs.jpcc. $6 \mathrm{~b} 07181$.

Villaluenga, I., Pesko, D. M., Timachova, K., Feng, Z. E., Newman, J., Srinivasan, V., et al. (2018). Negative Stefan-Maxwell diffusion coefficients and complete electrochemical transport characterization of homopolymer and block copolymer electrolytes. J. Electrochem. Soc. 165 (11), A2766-A2773. doi:10. 1149/2.0641811jes.

Wheatle, B. K., Keith, J. R., Mogurampelly, S., Lynd, N. A., and Ganesan, V. (2017). Influence of dielectric constant on ionic transport in polyether-based electrolytes. ACS Macro Lett. 6 (12), 1362-1367. doi:10.1021/acsmacrolett. $7 \mathrm{~b} 00810$.

Wieczorek, W., Florjanczyk, Z., and Stevens, J. R. (1995). Composite polyether based solid electrolytes. Electrochim. Acta 40 (13-14), 2251-2258. doi:10.1016/ 0013-4686(95)00172-b.

Wright, P. V. (1975). Electrical conductivity in ionic complexes of poly(ethylene oxide). Brit. Poly. J. 7 (5), 319. doi:10.1002/pi.4980070505

Yang, G., Ivanov, I. N., Ruther, R. E., Sacci, R. L., Subjakova, V., Hallinan, D. T., et al. (2018). Electrolyte solvation structure at solid-liquid interface probed by nanogap surface-enhanced Raman spectroscopy. ACS Nano 12 (10), 10159-10170. doi:10.1021/acsnano.8b05038.

Nanda, J., and Wu, P. Y. (2007). Crystallization process of poly( $\varepsilon$-caprolactone)poly(ethylene oxide)-poly( $\varepsilon$-caprolactone) investigated by infrared and twodimensional infrared correlation spectroscopy. Polymer 48 (12), 3477-3485. doi:10.1016/j.polymer.2007.04.021.

Zhang, H. C., and Wang, J. J. (2009). Vibrational spectroscopic study of ionic association in poly(ethylene oxide)-NH4SCN polymer electrolytes. Spectrochim. Acta Part A: Mol. Biomol. Spectrosc. 71 (5), 1927-1931. doi:10. 1016/j.saa.2008.07.018.

Zoller, P., and Walsh, D. J. (1995). Standard pressure-volume-temperature data for polymers. Lancaster, PA: Technomic Pub. Co.

Conflict of Interest: The authors declare that the research was conducted in the absence of any commercial or financial relationships that could be construed as a potential conflict of interest.

Copyright (c) $2020 \mathrm{Kim}$ and Hallinan Jr. This is an open-access article distributed under the terms of the Creative Commons Attribution License (CC BY). The use, distribution or reproduction in other forums is permitted, provided the original author(s) and the copyright owner(s) are credited and that the original publication in this journal is cited, in accordance with accepted academic practice. No use, distribution or reproduction is permitted which does not comply with these terms. 